\title{
Phase Transformations and Crack Initiation in a High-Chromium Cast Steel Under Hot Compression Tests
}

\author{
Jérôme Tchoufang Tchuindjang, Ingrid Neira Torres, Paulo Flores, Anne Marie Habraken, and Jacqueline Lecomte-Beckers
}

(Submitted November 19, 2014; in revised form February 23, 2015; published online March 12, 2015)

\begin{abstract}
The mechanical behavior of the fully austenitic matrix of high-chromium cast steel (HCCS) alloy is determined by external compression stress applied at 300 and $700{ }^{\circ} \mathrm{C}$. The microstructure is roughly characterized toward both optical and scanning electron microscopy analyses. Dilatometry is used during heating from room temperature up to austenitization to study the solid-state phase transformations, precipitation, and dissolution reactions. Two various strengthening phenomena (precipitation hardening and stress-induced bainite transformation) and one softening mechanism (dynamic recovery) are highlighted from compression tests. The influence of the temperature and the carbide type on the mechanical behavior of the HCCS material is also enhanced. Cracks observed on grain boundary primary carbides allow establishing a rough damage model. The crack initiation within the HCCS alloy is strongly dependent on the temperature, the externally applied stress, and the matrix strength and composition.
\end{abstract}

Keywords dilatometry, electron microscopy, internal damage, mechanical characterization, strengthening mechanism, tool steel

\section{Introduction}

High-chromium cast steels (HCCSs) are tool steels used in applications where sufficient wear resistance, high hot hardness, good oxidation behavior, and high fracture toughness are sought, these properties being also retained at elevated temperatures (Ref 1-3). A standard application for HCCS is the work roll of the roughing stand in the hot strip mill (HSM). In the case of cast work rolls, the initial chemical composition of the alloy, together with the solidification rate during the casting route, sets the grain size and the nature of the phases occurring in the solidification range, especially primary carbides often located at grain boundaries while forming a more or less continuous network (Ref 4, 5). These primary carbides represent the main parameter influencing the high hardness and the wear resistance of the alloy (Ref 4,6$)$.

The final properties of the material are promoted by the subsequent heat treatments following the casting route, which allow the formation of a martensitic matrix containing uniformly distributed secondary carbides that yield to enhanced

Jérôme Tchoufang Tchuindjang and JacquelineLecomte-Beckers, Division MMS, Department AME, Université de Liège, Liege, Belgium; Ingrid Neira Torres, Division MS2F, Department ArGEnCo, Université de Liège, Liege, Belgium and Department of Materials Engineering, Universidad de Concepción, Concepción, Chile; Paulo Flores, Department of Mechanical Engineering, Universidad de Concepción, Concepción, Chile; and Anne Marie Habraken, Division MS2F, Department ArGEnCo, Université de Liège, Liege, Belgium. Contact e-mails: j.tchuindjang@ulg.ac.be, inneira@udec.cl, pfloresv@udec.cl, anne.Habraken@ulg.ac.be, and jacqueline. Lecomte@ ulg.ac.be. hardness (Ref 4, 7, 8). Though work rolls for the roughing mill are massive parts weighing up to 40 tons, the heat treatment that follows the casting route must be handled carefully, while considering moderated heating and cooling rates in order to avoid distortions or detrimental residual stresses (Ref 9). In addition, soaking times for both hardening treatment and tempering might be long enough to allow, respectively, sufficient homogenization within the as-cast (AC) microstructure and adequate incubation time for carbide precipitation. The final mechanical properties of the work roll strongly depend on both the casting route and the subsequent thermal treatment (Ref 4-8).

Numerous studies have been undertaken to understand the work roll behavior during hot rolling in order to prevent or to better control both surface and internal damage. These works are related to both experimental and modeling studies, and different damage phenomena are involved, such as banding failure, thermal fatigue, fire cracking, wear, etc. (Ref 10). In addition, residual stress distribution within the work roll in service is also taken into account in order to reach accurate simulations (Ref 11).

Nevertheless, internal damage within the work roll during its fabrication and prior to service has received little attention so far.

Actually, it is still difficult to predict the behavior of such heavy parts, either at the end of the casting route or later during the subsequent heat treatment, due to the complex three-level coupling between the mechanics, metallurgy, and thermal fields. Specifically, there is a need to know the mechanical behavior of every single phase involved in the composition of the studied alloy, such as retained austenite, bainite, or martensite for the HCCS grade. For the existing damage mechanisms, little data are available (Ref 12, 13).

Indeed, specific studies focusing on the hot forging of tool steels are related either to the higher temperature range between 900 and $1100{ }^{\circ} \mathrm{C}$ or to the intermediate temperature range slightly below $700{ }^{\circ} \mathrm{C}$. The higher temperature range corresponds to hot forging processes where dynamic recrystalliza- 
tion, grain refinement, or decreasing primary carbide sizes are expected (Ref 14, 15). For the intermediate temperature range, a thermo-mechanical process also known as ausforming was developed which aims to plastically deform austenite at a constant temperature before its transformation (Ref 16). Such a process allows more or less dynamic recovery phenomenon, and at the same time, it has been reported to be very effective in refining the subsequent bainite/martensite structures which may later improve both strength and toughness (Ref 17, 18). Nevertheless, the two approaches previously quoted do not give the thermo-mechanical behavior of the austenite phase in tool steels. In fact, their main purpose is to achieve forging conditions that allow maximal strains under reduced stresses in order to produce a fine-grained structure at room temperature.

In addition, numerous works have been undertaken related both to the theoretical approach and to the simulation of the work hardening phenomenon in metals with a face-centered cubic (FCC) lattice, such as austenitic stainless steels, austenitic manganese steels, single crystals, and pure metals having low stacking fault energy (SFE). However, many of these studies focus on twinning, a phenomenon responsible for the subsequent enhanced ductility obtained on the material (Ref 19-21). Conversely, very few works have been undertaken on materials with a high SFE, such as HCCS grade material. The HCCS alloy studied in this paper is more like a high SFE material due to the high number of alloying elements, the precipitation inside the grains, and the micro-segregations at the grain boundaries.

The mechanical behavior of ultrahigh carbon steels at elevated temperatures is also investigated for various high strain rates to meet the requirements for developing dip die forging and other thermo-mechanical processing operations involving high deformations (Ref 22, 23). However, these studies deal with high SFE austenitic alloys. They mostly focus on the optimization of material formability through the construction of the deformation mechanism maps and the determination of the maximum ductility. Nevertheless, the main objectives of the abovementioned works are quite far removed from the enhancement of the strengthening behavior of complex austenite phase with higher SFE, such as the HCCS involved in this work, in the intermediate and especially in the lower temperature ranges.

The current study forms a basis for the subsequent simulation of the thermo-mechanical behavior of the shell material of cast work rolls which contain different types of carbides (Ref 9).

The strengthening behavior of austenite in the studied HCCS alloy combines different hardening and softening phenomena. The current analysis enhances their specific contribution to the overall material behavior. This study chooses both an intermediate temperature and a low temperature for the compression tests performed together with two heating rates that allow obtaining more or less undissolved transition carbides within the matrix.

\section{Material and Experimental Methods}

\subsection{Raw Material and Sampling}

The studied alloy is an HCCS grade originating from the shell material of a work roll obtained from a vertical spin casting process and dedicated to the roughing stands of an HSM. The work roll has an outer diameter of $1200 \mathrm{~mm}$ and a shell depth of $80 \mathrm{~mm}$. The average chemical composition of the
HCCS alloy as obtained from optical emission spectroscopy is given in Table 1.

Rough cylindrical samples with their axes parallel to that of the work roll are cut out within the first $20 \mathrm{~mm}$ over the entire $80-\mathrm{mm}$ depth of the shell material. The samples are located close to the end of the barrel. The sizes of the cylindrical samples range between 5 and $10 \mathrm{~mm}$ for the diameter, and between 5 and $25 \mathrm{~mm}$ for the length, depending on the final test to be performed (Fig. 1).

The cylindrical specimens are obtained from an electrodischarge machining process. A preliminary metallographic preparation consisting of a hot mounting with epoxy resin followed by grinding and polishing down to $1 \mu \mathrm{m}$ is performed prior to final super polishing down to $0.06 \mu \mathrm{m}$ with colloidal silica, which is an active oxide polishing suspension (OPS). Elsewhere, classical nital etching is undertaken on stressed and polished samples in order to better reveal the phases within the matrix and to enhance transformation of parent austenite into hardened phases (bainite, martensite).

\subsection{Experimental Methods}

Heat treatment is undertaken on cylinders coming from HCCS blocks in the AC conditions, to allow both rehomogenization and hardening in the studied alloy. The socalled HT (heat-treated) samples are generated from this heat treatment as illustrated in the flow chart process given in Fig. 1. HT samples are the starting point for further experimental analyses, such as dilatometry or compression tests.

The compression tests are carried out with a SCHENCK Hydropuls $400 \mathrm{kN}$ machine using a quad elliptical heater $4 \times 2000 \mathrm{~W}$, with a constant strain rate of $3 \times 10^{-3} \mathrm{~s}^{-1}$. Two heating rates are used on the HT samples when reheating them up to $950{ }^{\circ} \mathrm{C}$ : a high heating rate of $2{ }^{\circ} \mathrm{C} \mathrm{s}^{-1}$ (A cycle) and a low heating rate of $1{ }^{\circ} \mathrm{C} \mathrm{s}^{-1}$ (B cycle). Once the austenitizing temperature is reached, the cooling stage is obtained inside the furnace down to the temperature of the compression test, which is either set at 700 or at $300{ }^{\circ} \mathrm{C}$. For a given heating rate $\mathrm{A}$ or $\mathrm{B}$, each compression test is performed twice. In addition, in order to analyze the pure effect of the thermal cycle on the microstructure in the furnace used for compression tests, the thermal cycle B is run on a single additional sample without applying any compression stress.

Microstructure characterization is carried out at different stages of the work using various techniques such as optical microscopy (OM), scanning electron microscopy (SEM), and Vickers hardness measurements.

OM observations are made on an OLYMPUS BX60 microscope coupled with an OLYMPUS UC30 CCD digital camera and equipped with a motorized stage together with the OLYMPUS STREAM Motion ${ }^{\circledR}$ software. OM analyses are performed on longitudinal sections of cylindrical samples originated from AC, HT, and compression test (CT) conditions (Fig. 1).

SEM analyses are performed on a PHILLIPS XL 30 FEGESEM equipped with a 129 eV BRUKER energy dispersive $\mathrm{x}$ ray spectrometer (EDS) with a silicon drift detector (SDD), the system being connected to ESPRIT ${ }^{\circledR}$ software for pre- and posttreatment of the data. The SEM allows identification of the matrix phases and carbides greater in size than one micron. Such a technique is not appropriate for thin precipitates as small as some nanometers.

The transmission electron microscopy (TEM) technique, often used for both dislocations and nanoscale precipitate 
Table 1 Average chemical composition (weight \%) of the HCCS alloy

\begin{tabular}{|c|c|c|c|c|c|c|c|c|}
\hline & C & $\mathbf{S i}$ & Mn & $\mathbf{N i}$ & $\mathrm{Cr}$ & Mo & $\mathbf{V}$ & $\mathbf{F e}$ \\
\hline Min & 1.0 & 0.2 & 0.6 & 0.5 & 10.0 & 3.0 & 0.1 & Base \\
\hline Max & 1.5 & 1.0 & 1.0 & 1.5 & 14.0 & 6.0 & 0.5 & \\
\hline
\end{tabular}



Fig. 1 Flow chart for the sampling and the experimental tests on HCCS alloy

studies, was discarded due to difficulties in preparing thin foil samples. With the available electro polishing device, carbides within the HCCS alloy remain undissolved during the preparation. Instead, dilatometry tests are carried out on HT samples, on a NETZSCH DIL 402C apparatus. Dilatometric tests consist of a reheating stage up to $960{ }^{\circ} \mathrm{C}$ prior to cooling down to room temperature. Two constant heating rates of 2 and $20{ }^{\circ} \mathrm{C} \mathrm{min} \mathrm{min}^{-1}$ are used, while a single cooling rate of $20{ }^{\circ} \mathrm{C} \mathrm{min} \mathrm{min}^{-1}$ is run. The dilatometry technique is used to detect tertiary carbides within the HT HCCS material, and to measure the critical temperatures for their precipitation and their subsequent dissolution. In addition, such a test helps to determine the coefficient of thermal expansion (CTE) of the phases existing in the studied sample.

Hardness measurements are done on a universal EMCO MC10 010 machine with an electronic cell force and closed loop regulation. Both micro-( $\mathrm{HV}_{1}$ for $1 \mathrm{~kg}$ load $)$ and macro$\left(\mathrm{HV}_{30}\right.$ for $30 \mathrm{~kg}$ load) Vickers hardness are obtained in order to, respectively, assess the matrix hardness and the bulk hardness. For each sample, the average hardness value is obtained from 3 or 5 indentation points, respectively, for the micro-hardness (inside single grains) and for the macrohardness (bulk hardness for about twenty grains including carbides located at grain boundaries).

Grain size measurements and primary carbide volume fractions are obtained using image processing software on compressed specimens. Grain size is obtained following the planimetric method (ASTM E112 chart). The carbide volume fraction is assessed while considering all the grain boundary carbides as a whole. The results of carbide quantification may represent the upper limit for their actual volume fraction within the studied samples. The main parameters for the setting of the quantitative metallography (grain size measurements and carbide quantification) are given in Table 2.

Sample designations with the related applied thermal cycle and heating rate are summarized in Table 3. Hereinafter, the following designations AC, HT, CT300, and CT700, will be used, respectively, for the as-cast sample, the heat-treated sample, the sample re-austenitized prior to the compression test at $300{ }^{\circ} \mathrm{C}$, and the sample re-austenitized prior to the compression test at $700{ }^{\circ} \mathrm{C}$. For the compressed samples, an additional letter, $\mathrm{A}$ or $\mathrm{B}$ that refers to the heating rate, can be used. The sample re-austenitized and cooled down to room temperature without applying any stress will be called the stress-free sample or SF300.

\section{Results}

In this work, the morphology, the distribution, and the chemical composition of the so-called primary and secondary 
Table 2 Samples and setting used for grain size and primary carbide volume fraction assessment toward optical microscopy

\begin{tabular}{llccccc}
\hline $\begin{array}{l}\text { Sample } \\
\text { designation }\end{array}$ & $\begin{array}{c}\text { Overall section } \\
\text { size }(\mathbf{m m})\end{array}$ & $\begin{array}{c}\text { Orientation of } \\
\text { the section }\end{array}$ & $\begin{array}{c}\text { Frame resolution } \\
\text { (pixels) }\end{array}$ & $\begin{array}{c}\text { Area/frame } \\
\left.\mathbf{( m m}^{\mathbf{2}}\right)\end{array}$ & $\begin{array}{c}\text { Total number } \\
\text { of frames }\end{array}$ & $\begin{array}{c}\text { Ratio of the sampled } \\
\text { region over the total area (\%) }\end{array}$ \\
\hline $\begin{array}{l}\text { CT300-A } \\
\text { CT300-B }\end{array}$ & $\begin{array}{l}\text { Height } 5 \\
\text { Width } 9\end{array}$ & $\begin{array}{c}\text { L } \\
\text { CT700 }\end{array}$ & (// roll axis) & $2592 \times 1944$ & 5.8 & 3 \\
\end{tabular}

Table 3 Summary of the thermal cycles applied during reheating up to $950{ }^{\circ} \mathrm{C}$, and temperature of the subsequent compression tests performed during the subsequent cooling stage inside the furnace

\begin{tabular}{|c|c|c|c|}
\hline $\begin{array}{l}\text { Temperature for } \\
\text { the compression tests }\end{array}$ & Sample designation & $\begin{array}{l}\text { Number of } \\
\text { samples }\end{array}$ & $\begin{array}{l}\text { Heating rate achieved up to } \\
950^{\circ} \mathrm{C} \text {, prior to compression test }\end{array}$ \\
\hline \multirow[t]{2}{*}{$300{ }^{\circ} \mathrm{C}$} & СТ300-A & 2 & $2{ }^{\circ} \mathrm{C} / \mathrm{s}$ \\
\hline & СТ300-В & 2 & $1{ }^{\circ} \mathrm{C} / \mathrm{s}$ \\
\hline Stress-free & SF300-B & 1 & $1{ }^{\circ} \mathrm{C} / \mathrm{s}$ \\
\hline \multirow[t]{2}{*}{$700{ }^{\circ} \mathrm{C}$} & CT700-A & 2 & $2{ }^{\circ} \mathrm{C} / \mathrm{s}$ \\
\hline & CT700-B & 2 & $1{ }^{\circ} \mathrm{C} / \mathrm{s}$ \\
\hline
\end{tabular}

carbides are mentioned in section 3.1. In addition, the critical temperatures for both the primary and the secondary carbides are measured according to the specific nomenclature, determined in a previous study (Ref 24), reproduced hereafter:

- Primary carbides are eutectic types composed of $\mathrm{Cr}$-rich $\mathrm{M}_{7} \mathrm{C}_{3}$ or Mo-rich $\mathrm{M}_{2} \mathrm{C}$ that precipitate from the liquid at grain boundaries during the solidification process. They exhibit both lamellar and rod-like morphologies. Their main sizes range between 5 and $50 \mu \mathrm{m}$ and they form at a single temperature for each, which is above $1100{ }^{\circ} \mathrm{C}$.

- Secondary carbides precipitate around $1050{ }^{\circ} \mathrm{C}$ from the supersaturated austenite, in continuous cooling conditions during the casting route and just after the solidification process. These carbides are composed of Cr-rich $\mathrm{M}_{23} \mathrm{C}_{6}$ widespread inside grains, which define, at the same time around their cluster, a band strip also known as the "precipitate-free zone" (PFZ) that is close to the grain boundaries. They are mainly globular shaped, with sizes between 1 and $3 \mu \mathrm{m}$.

The mechanical results, microstructure characterization, and hardness and quantitative metallography are, respectively, given in sections 3.2, 3.3, and 3.4. Discussions involving various strengthening and softening mechanisms and the internal damage phenomena occurring within the compressed HCCS alloy are addressed in section 4, together with the development of a rough damage model. In particular, two extended studies based on the literature and the current results are proposed. Sections 4.2 and 4.3 provide, respectively, for the bainite transformation and for the carbides, the strengthening mechanism that occurs in the HCCS alloy.

\subsection{Solid-State Transformations and Precipitation/ Dissolution Reactions from the Dilatometry Study}

Microstructures in the AC conditions, and after the rehomogenization and hardening heat treatment, are illustrated in Fig. 2.

The microstructures in both the AC (Fig. 2a) and HT (Fig. 2b) samples are quite similar, with a quasi-continuous network of carbides at grain boundaries and a mixed matrix composed of both fresh martensite $\left(\alpha^{\prime}\right)$ and retained austenite $(\gamma)$. In addition, troostite is only present in the AC samples (Fig. 2a). The heat treatment undertaken on the AC samples allows full dissolution of the troostite phase into austenite prior to the subsequent martensitic transformation during air cooling. The final microstructure obtained on the HT samples exhibits enhanced bulk hardness as it is mainly composed of a martensitic matrix with a small amount of retained austenite (Table 4). Primary and secondary carbides are assumed to remain similar in the $\mathrm{AC}$ conditions and after re-homogenizing treatment because the austenitization temperature chosen is below the critical temperature at which the dissolution of secondary carbides begins.

The chemical distribution of elements within both the carbides and the matrix as obtained from the SEM-EDS analysis of the HT samples is illustrated in Fig. 3.

It appears that both primary $\mathrm{Cr}$-rich $\mathrm{M}_{7} \mathrm{C}_{3}$ and Mo-rich $\mathrm{M}_{2} \mathrm{C}$ carbides are mainly large eutectic carbides located at grain boundaries in a quasi-continuous network. These carbides exhibit constant chemical composition for each type. There are intragranular secondary $\mathrm{Cr}$-rich $\mathrm{M}_{23} \mathrm{C}_{6}$ carbides that form clusters inside grains, with a chemical composition that changes depending on the carbide location. The Mo content in secondary carbides seems to be higher for precipitates located close to the grain boundaries than those in the center of the grain. In addition, the $\mathrm{M}_{23} \mathrm{C}_{6}$ carbide clusters leave around and close to the grain boundaries the so-called PFZs that describe annular strips without visible carbides inside.

Dilatometric curves obtained on the HT samples during the reheating stage up to $960{ }^{\circ} \mathrm{C}$ under two constant heating rates of 2 and $20^{\circ} \mathrm{C} \mathrm{min}^{-1}$ are given in Fig. 4, with the illustration of the CTE related to the phases that are present within the matrix.

Both HT samples exhibit a small expansion well below the $\mathrm{Ac}_{1}$ point, which corresponds to fresh martensite $\left(\alpha^{\prime}\right)$ decomposition that also involves the formation of ferrite $(\alpha)$ and cementite $(\theta)$. This phase transformation occurs earlier under a low heating rate compared to the high heating rate. In addition, 


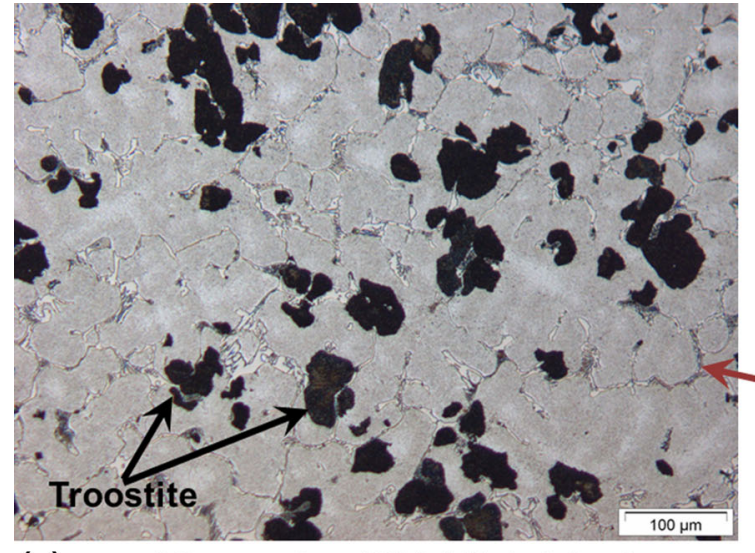

(a) AC samples (OM, Nital etched)

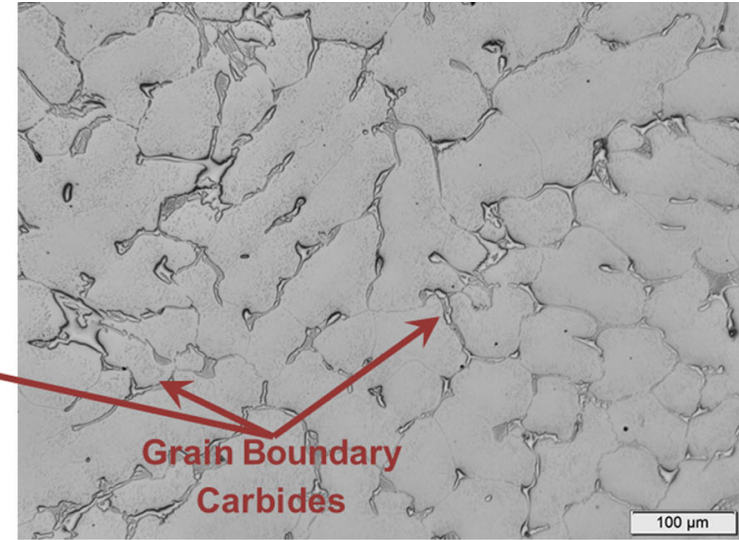

(b)

HT samples (OM, OPS)

Fig. 2 Microstructure (optical micrographs) of the HCCS alloy in the as-cast conditions (AC samples) and after heat treatment (HT samples)

Table 4 Average Vickers hardness of the HCCS alloy after various thermo-mechanical treatments

\begin{tabular}{|c|c|c|c|}
\hline \multirow{2}{*}{$\begin{array}{l}\text { Sample } \\
\text { designation }\end{array}$} & \multirow{2}{*}{$\begin{array}{c}\text { Macro-hardness } \\
\text { measurements }\left(\mathrm{HV}_{30}\right) \\
\text { in bulk material }\end{array}$} & \multicolumn{2}{|c|}{$\begin{array}{c}\text { Micro-hardness measurements } \\
\left(\mathrm{HV}_{1}\right) \text { with a single indentation } \\
\text { inside each grain }\end{array}$} \\
\hline & & Grains with bainite sheaf structure & Grains free of bainite sheaf structure \\
\hline $\mathrm{AC}$ & $582 \pm 7$ & $\ldots$ & $\ldots$ \\
\hline HT & $805 \pm 9$ & $\ldots$ & $\ldots$ \\
\hline СТ300-A & $622 \pm 4$ & $599 \pm 22$ & $634 \pm 0$ \\
\hline СТ300-B & $664 \pm 8$ & $653 \pm 4$ & $685 \pm 8$ \\
\hline CT700-A & $652 \pm 6$ & $635 \pm 2$ & $649 \pm 3$ \\
\hline \multicolumn{4}{|l|}{ СТ700-B } \\
\hline SF300-B & $613 \pm 10$ & $603 \pm 12$ & $640 \pm 16$ \\
\hline
\end{tabular}

the thermal expansion of the reheated HT samples seems to be higher with the low heating rate. Moreover, $\mathrm{Ac}_{1}$ and $\mathrm{Ac}_{3}$ corresponding, respectively, to the start point and to the end point of the austenite transformation are shifted to higher temperatures on increasing the heating rate.

Solid-state transformations with their related critical points, which are clearly identified on the dilatometric curves, may correspond to the following sequence: the $\alpha^{\prime}$-fresh martensite decomposition, the $\gamma_{0}$-austenite transformation, and the dissolution of $\theta$-cementite into $\gamma_{0}$ to yield $\gamma_{1}$-austenite well above $\mathrm{Ac}_{3}$. The later reaction is only observed on the HT sample with the low heating rate. The subscript ( $i=0$ or 1$)$ used for austenite $\left(\gamma_{i}\right)$ is intended to illustrate the difference within the chemical composition of the related phase. In fact, $\gamma_{1}$ that results from the dissolution of $\theta$ into $\gamma_{0}$ is more saturated in $\mathrm{C}$ than the parent $\gamma_{0}$ phase that comes from the transformation of $\alpha$.

The increase in the heating rate seems to delay both the $\alpha^{\prime}$-martensite decomposition and the $\gamma_{0}$-austenitization range $\left(\mathrm{Ac}_{1}\right.$ and $\left.\mathrm{Ac}_{3}\right)$, to higher temperatures.

Dilatometric curves exhibit three consecutive steady stages I, II, and III, which are represented by three constant slopes, each stage having a constant CTE that may be related to one or more "stable" phases (Fig. 4). The first stage is related to $\alpha^{\prime}$ martensite phase (a small amount of retained austenite can be present), the second to both $\alpha$-ferrite and $\theta$-cementite, and the third to $\gamma_{0}$-austenite. The first two stages are below the $\mathrm{Ac}_{1}$ point, while the third is above the $\mathrm{Ac}_{3}$ point. Any change in the slope of the curve corresponds either to a phase transformation or a precipitation/dissolution reaction. The corresponding CTE of $\alpha^{\prime}$ ranges between the lowest one subsequently obtained on $\alpha+\theta$, and the highest one achieved on $\gamma_{1}$, at the end of the heating mode (Fig. 4). The decrease in the CTE of the newly formed $\alpha$-ferrite compared to that of $\alpha^{\prime}$-martensite is expected as the tetragonal crystal lattice of the martensite is more saturated in interstitial atoms than the body-centered cubic lattice of the ferrite.

The decomposition of the $\alpha^{\prime}$-martensite into $\alpha$-ferrite and the newly precipitated $\theta$-cementite yields a small expansion in the dilatometric curve, while the allotropic transformation of $\alpha$ ferrite into $\gamma_{0}$-austenite occurs under significant contraction (Fig. 4).

Moreover, the HT sample reheated under the low heating rate seems to exhibit a CTE slightly higher than that of the sample with a high heating rate, just above the $\mathrm{Ac}_{3}$ point (Fig. 4). This phenomenon is well enhanced when cooling curves are considered for both samples due to the difference between the initial thermal expansion of the $\gamma$-austenite phase during the heating mode, and the corresponding contraction coefficient of the same phase during the subsequent cooling mode. Such a difference only exists for the HT sample with the low heating rate (Fig. 4), and it may correspond to $\theta$-cementite dissolution into $\gamma$-austenite. This result is in good agreement with Chae et al. (Ref 25) who found that cementite dissolution 

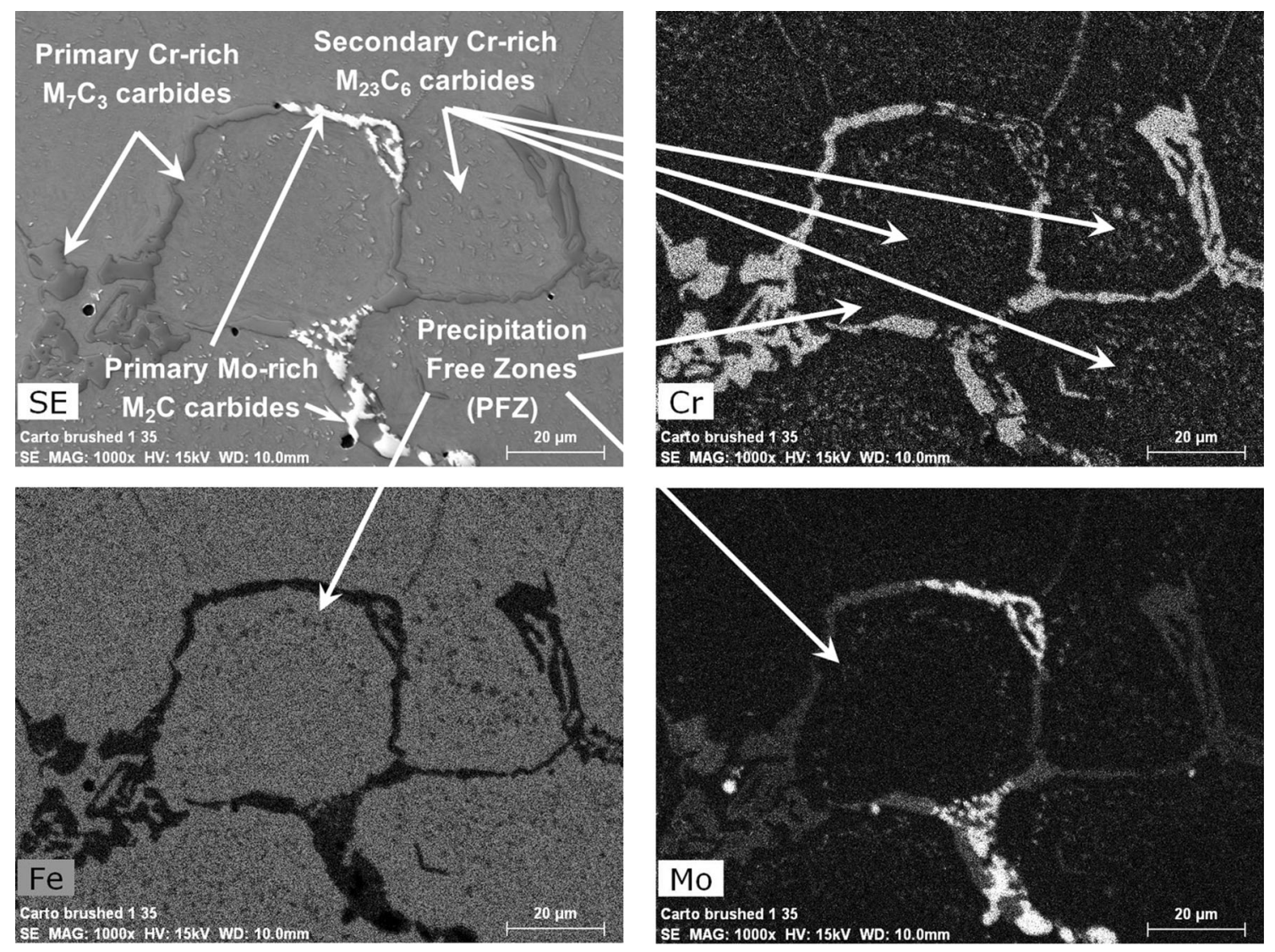

Fig. 3 EDS-map of HT samples enhancing carbide distribution and composition

in the austenite matrix under continuous heating conditions yields non-linear behavior on the dilatometry curve.

Therefore, it can be concluded that the matrix of HT samples at $960{ }^{\circ} \mathrm{C}$ is composed of $\gamma_{0}+$ undissolved $\theta$-cementite when the reheating rate is as high as $20^{\circ} \mathrm{C} \mathrm{min}^{-1}$. The same samples reheated at $2{ }^{\circ} \mathrm{C} \min ^{-1}$ may exhibit a matrix composed of a singe $\gamma_{1}$ phase, where $\theta$-cementite precipitates are almost fully dissolved.

\subsection{Flow Stress Curves and Work Hardening Rates of the HCCS Alloy}

The thermal histories measured during the time spent by the samples in the furnace for the CTs are illustrated in Fig. 5(a) below. The related flow stress curves obtained from the CTs (logarithmic strain-true stress) are given in Fig. 5(b).

Flow stress curves show a hardening stage that increases with decreasing compression temperatures. All the samples subjected to the low heating rate of $1^{\circ} \mathrm{C} \mathrm{s}^{-1}$ prior to the $\mathrm{CT}$, performed either at 700 or at $300{ }^{\circ} \mathrm{C}$, exhibit similar flow stress curves. Therefore, the average between both curves is calculated and is considered hereinafter. In addition, flow stress curves obtained from the CT700-A samples are almost identical to the average of the CT700-B samples. This suggests similar hardening behavior for the batch of samples tested at $700{ }^{\circ} \mathrm{C}$, regardless of the prior reheating rate up to the austenitizing temperature. The four samples tested at $700{ }^{\circ} \mathrm{C}$ will be referred to as CT700 hereinafter, irrespective of the heating rate used prior to the CTs.

Conversely, different mechanical behavior is observed between the two samples reheated at $2{ }^{\circ} \mathrm{C} \mathrm{s}^{-1}$ (CT300-A) and the two other samples reheated at $1{ }^{\circ} \mathrm{C} \mathrm{s}^{-1}$ (CT300-B) prior to the CTs performed at $300{ }^{\circ} \mathrm{C}$ (Fig. 5b). The CT300-A samples exhibit the higher hardening effect, while maximum elongation has been achieved on the CT300-B samples.

The work hardening rate curves of all the tested samples are illustrated in Fig. 6. The work hardening rate curves present a decreasing trend below $0.02 \%$ logarithmic strain, before reaching the same asymptote above this limit. The decreasing trend in the work hardening rate is higher for the CT300-A samples, probably because the maximum strength reached is many times higher than that of the other samples.

\subsection{Microstructures After the CTs}

The microstructures obtained after the CTs performed at $300{ }^{\circ} \mathrm{C}$ are illustrated in Fig. 7 and 8, respectively, for the high (CT300-A) and for the low (CT300-B) heating rates.

The CT300-A samples contain bainite with preferential oriented sheaves, the rest of the matrix being composed of fresh martensite and possibly retained austenite (Fig. 7a). The bainite sheaf structure probably resulted from the compression stress applied to the sample. The crack path observed in the CT300-A samples is composed of single oriented cracks within the grain boundary carbides, these cracks being parallel to the externally applied stress (Fig. 7b). In addition, evidence of the secondary carbide's widespread inside grains is enhanced in the optical micrograph after OPS preparation (Fig. 7c).

The CT300-B samples exhibit bainite with oriented sheaves in their matrix, and either martensite or some retained austenite in addition (Fig. 8a). The crack path in the CT300-B clearly 


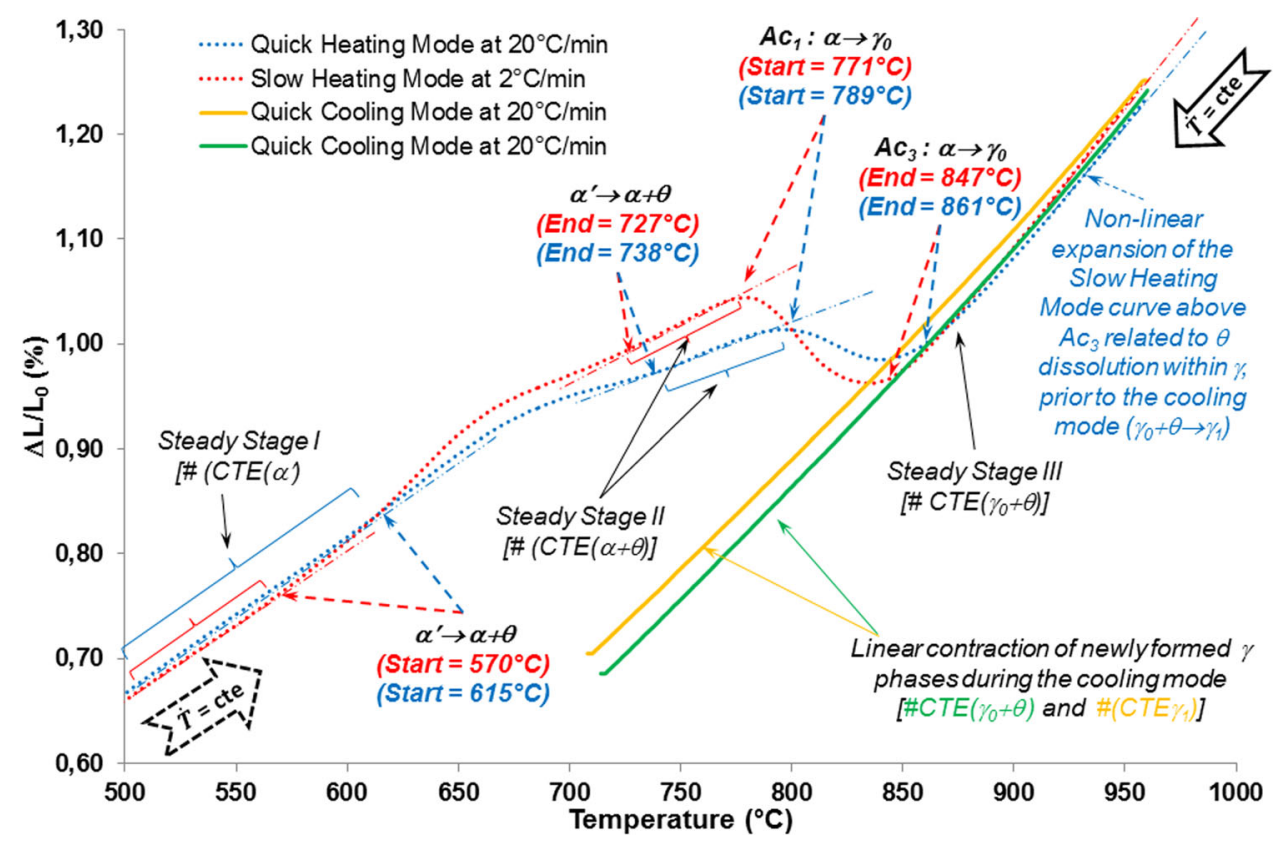

Fig. 4 Enhancement of the effect of heating rate on the phase transformations of HT samples during dilatometry tests
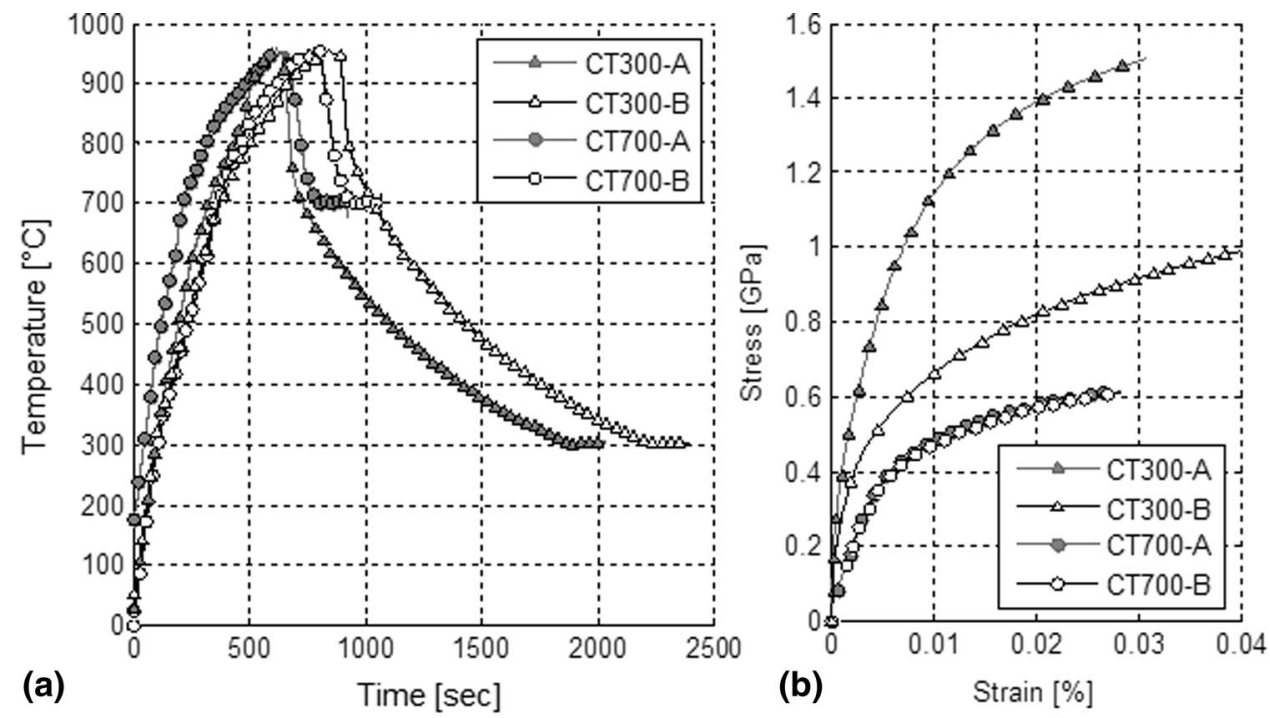

Fig. 5 (a) Thermal histories of the compression samples (b) Flow stress curves obtained after compression test performed during cooling stage either at 700 or at $300{ }^{\circ} \mathrm{C}$

looks more complex and more extended than the previous one observed in CT300-A, due to the branching that occurs within the cracks (Fig. $8 \mathrm{~b}$ ). But the primary cracks remain parallel to the stress direction. Similar to CT300-A, evidence of numerous intragranular secondary carbides is enhanced in the optical micrograph after OPS preparation (Fig. 8c). In addition, the corrosion pits observed on the CT300-B are probably due to the infiltration of the nital etching into the large cracks that exist within the primary carbides (Fig. 8a). PFZs still exist on the CT300 samples (Fig. 7c and 8c).

For the CT700 samples (Fig. 9), very few large oriented bainitic sheaves are observed inside the grains, the rest of the matrix being composed of martensite and retained austenite
(Fig. 9a). This later phase is probably present in an amount higher than that of the previous CT300 samples. Such an assumption can be supported by two observations. First, the apparent volume fraction of the bainitic sheaves in the CT700 samples seems to be lower than that observed within the CT300 samples. Second, the low sensitivity of the etched sample to the nital reagent suggests that the austenite phase which remained un-etched is present in a significant amount.

While all the compressed samples seem to exhibit preferential oriented bainitic sheaves in various amounts and sizes, the stress-free SF300 sample contains large quantities of sheave-like bainite structures with haphazard oriented directions inside the grains (Fig. 10a). In addition, the grain 


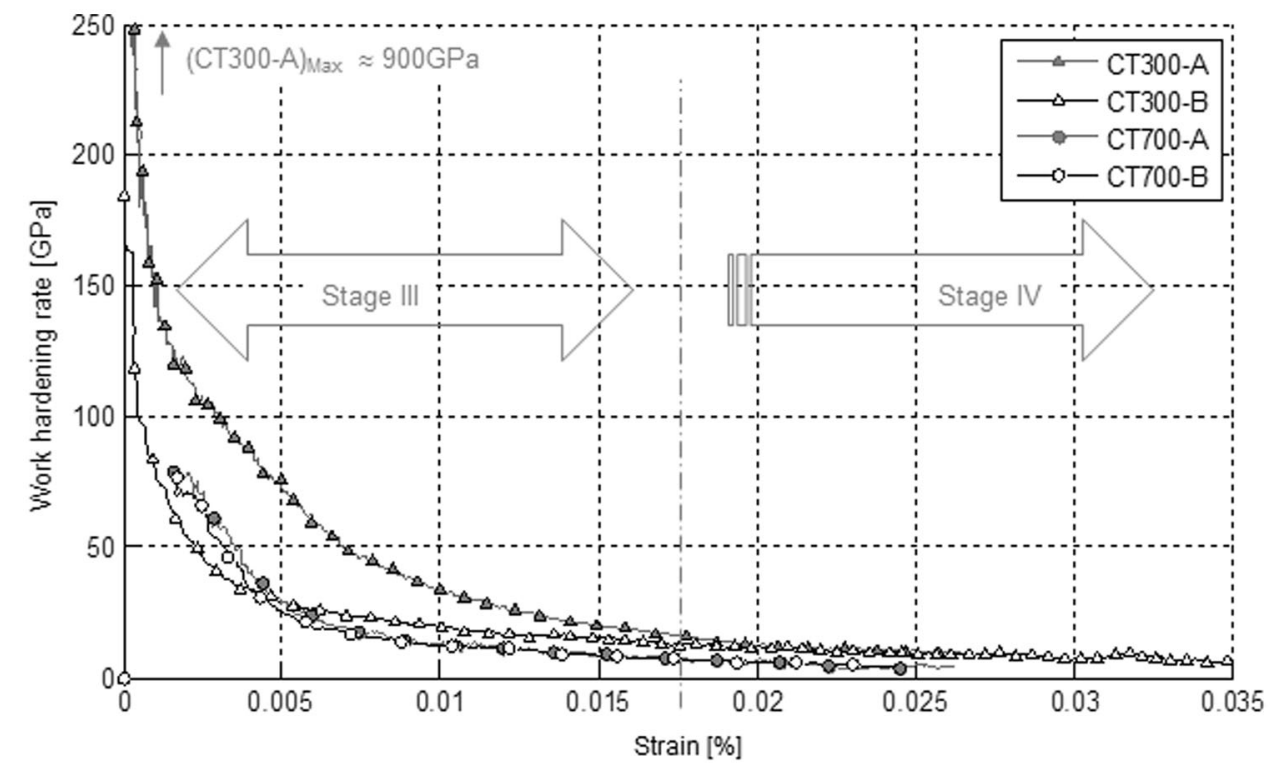

Fig. 6 Work hardening rate curves for HCCS material at 300 and $700{ }^{\circ} \mathrm{C}$

boundary carbides do not exhibit cracks as no external stress was applied. Widespread secondary carbides are present inside the grains with PFZs around them (Fig. 10b), such an observation being similar to the previous ones made on the compressed samples.

\subsection{Hardness Measurements, Grain Size, and Carbide Content}

Hardness values are given in Table 4 with bulk hardness corresponding to macro-hardness, and micro-hardness corresponding to local hardness inside the grains. Hardness measurements are located in two different zones or grains, the first one containing bainite sheaf structure and the second one being free of bainite. This latter zone probably corresponds to the martensite phase with very low retained austenite. The average macro-hardness ranges between the two extreme values found for micro-hardness inside the grains, except for the CT700 samples where it is close to the higher micro-hardness values obtained.

The maximum macro-hardness is achieved on the HT samples, which contain a higher amount of martensite with a reduced quantity of retained austenite. In addition, no bainitic phase is found in these samples.

The lower bulk hardness value is obtained on the $\mathrm{AC}$ samples, probably due to the presence of the softer troostite phase (Fig. 2a).

Among the micro-hardness values, the lowest ones that correspond to $599 \mathrm{HV}_{1}$ and $634 \mathrm{HV}_{1}$ are obtained for the CT300-A samples, respectively, within grains containing bainitic sheaves and in grains without bainite phase. The CT700 samples exhibit hardness values that are inserted between those of the CT300-A and CT300-B for both macroand micro-hardness. For the SF300-B sample, the minimum of the micro-hardness $\left(603 \mathrm{HV}_{1}\right)$ is observed inside the grains containing bainite sheaf structure, while the maximum of 640 $\mathrm{HV}_{1}$ is obtained inside the bainite-free grains.
The maximum for the standard deviation has been measured within the CT300-A samples, probably due to very large discrepancies within the progress of the bainite-oriented transformation inside the grains.

The hardness measurements for the compressed samples confirm the strong differences within the HCCS behavior as observed in both the AC and HT samples. Section 4.5 will link these results to the microstructures generated during the heating, cooling, and, finally, the compressed states.

The results of the grain size and carbide content assessments are given in Table 5. Both the grain size and the volume fraction of the primary carbides are similar for all the compressed samples after the CTs.

\section{Discussion}

\subsection{Work Hardening Rate in Compressed Samples}

The work hardening rate curves of all the tested samples represent Stage III and Stage IV (Fig. 6) as described by Kalidindi for FCC polycrystals with high SFE, for which plastic deformation proceeds by slip alone, contrary to low SFE FCC metals (plastic deformation by both slip and twinning) (Ref 20). In addition, the first two stages (Stage I and Stage II) predicted by Kocks and Mecking (Ref 21), which are well defined for single crystal materials with low SFE, are reported to be hardly observed for FCC polycrystals with high SFE, which are similar to the HCCS alloy studied in this work.

In polycrystalline metals deforming by slip alone, the strain hardening response primarily comprises a dynamic recovery regime (Stage III) in which the strain hardening rate continuously decreases with increasing flow stress or imposed strain (Ref 20). At high strain rates, Stage III of such alloys may turn into Stage IV which corresponds to the region for low hardening rates where an asymptote for high strain is set (Ref 20, 21). 


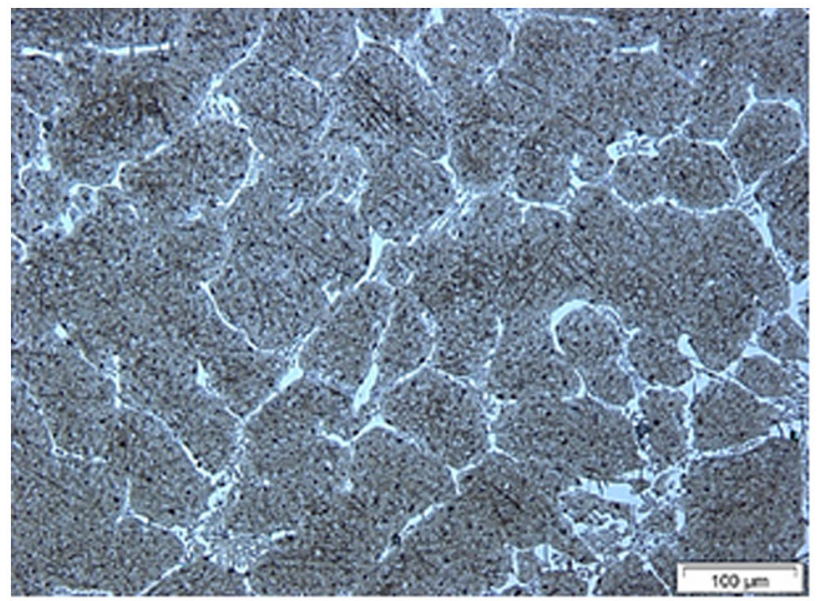

(a) Very few preferential oriented bainite sheaves in the matrix in association with martensite (OM, Nital etched)

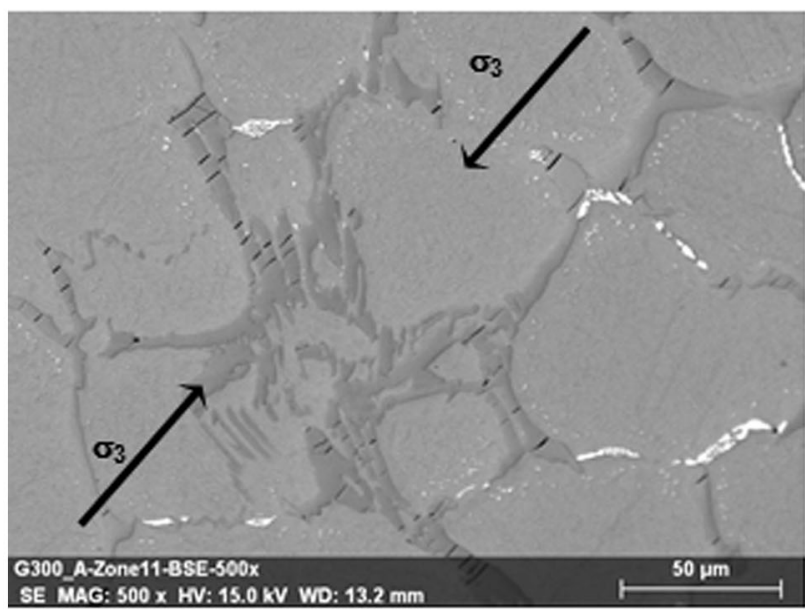

(b) Single orientation for the crack path inside primary carbides, in a direction similar to the external compression stress $\sigma_{3}$ (SEM-BSE, OPS)

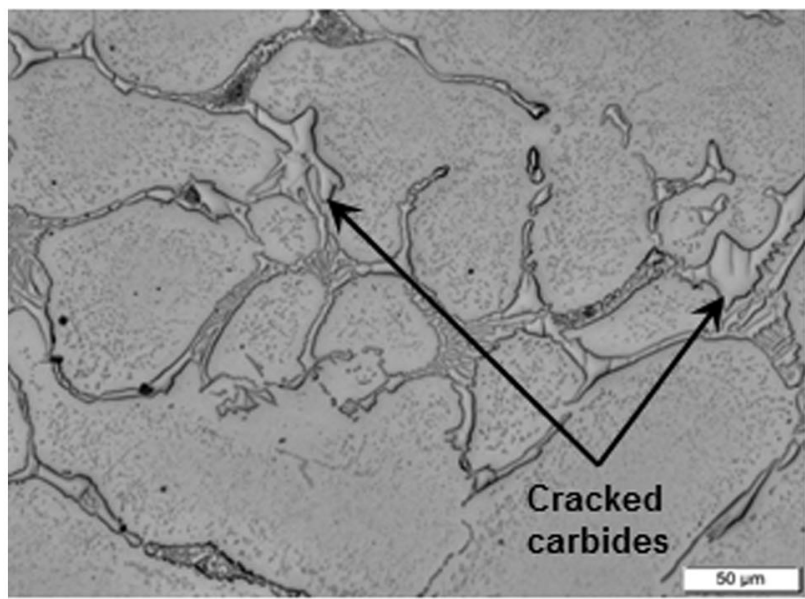

(c) Widespread secondary carbides inside grains, PFZ, and cracked grain boundary primary carbides (OM, OPS)

Fig. 7 Microstructures obtained after compression tests on CT300-A samples



(a) Numerous preferential oriented bainite sheaves in the matrix, and pitting corrosion around primary carbides (OM, Nital etched)

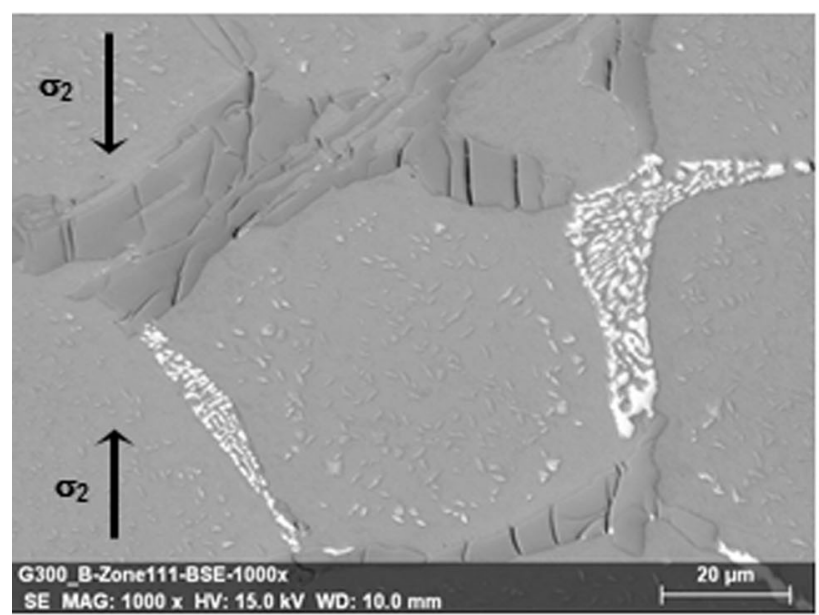

(b) Multiple orientation for the crack path on primary grain boundary carbides, large cracks being parallel to the stress $\sigma_{2}$ (SEM-BSE, OPS)

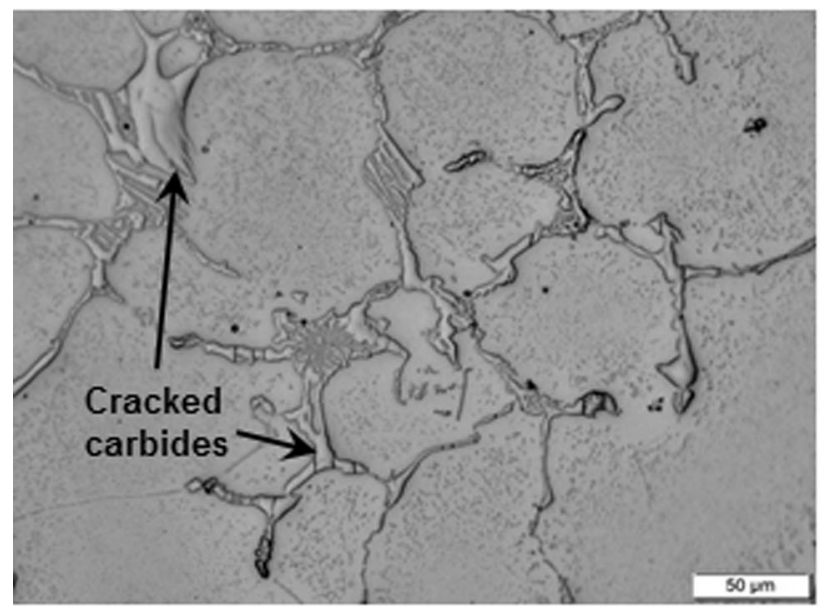

(c) Numerous intragranular secondary carbides, PFZ, and multiple cracked primary carbides at grain boundaries (OM, OPS)

Fig. 8 Microstructures obtained after compression tests on CT300B samples 


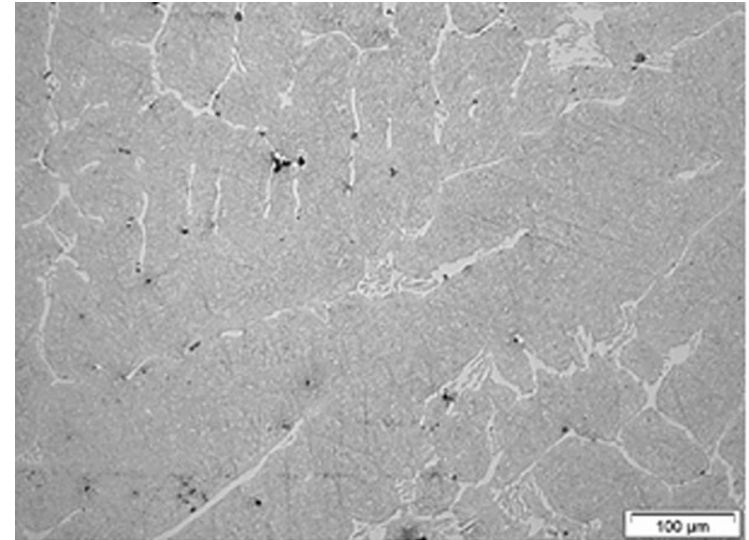

(a) Very few preferential oriented bainite sheaves in the matrix in association with martensite and retained austenite (OM, Nital etched)

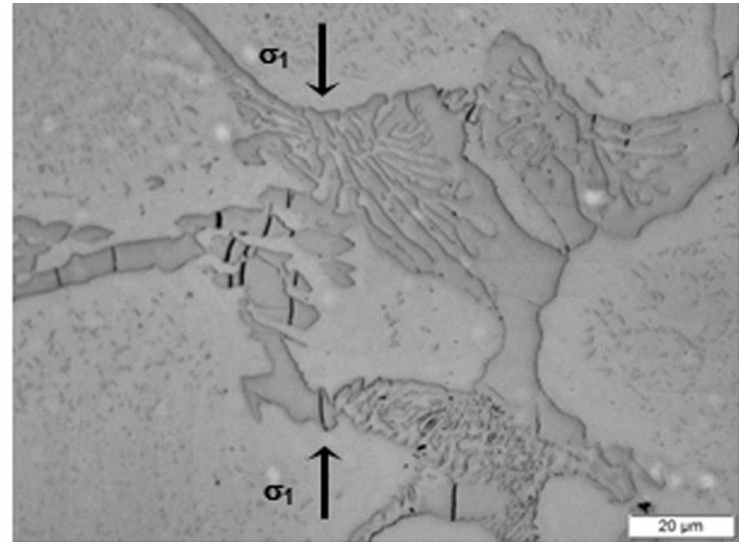

(b) Cracks initiated on grain boundaries primary carbides parallel to the external applied stress $\sigma_{1}$; intragranular secondary carbides with PFZ around (OM, OPS)

Fig. 9 Microstructures obtained after compression tests on CT700 samples

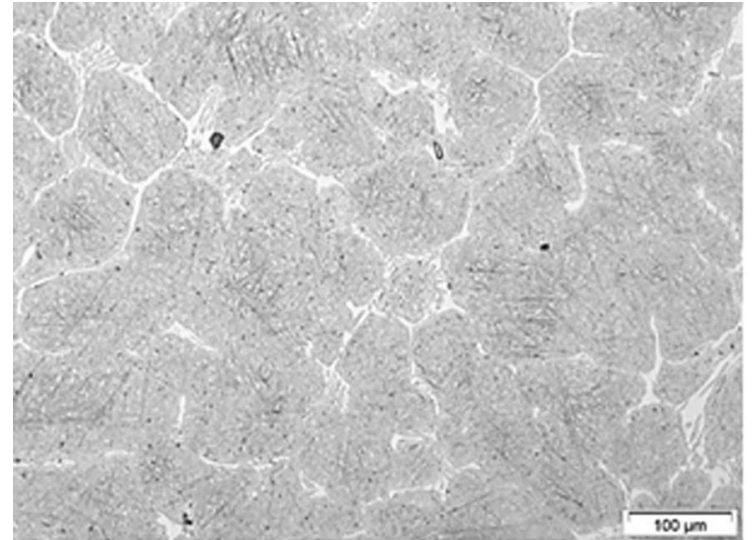

(a) Numerous bainitic sheaves haphazardly distributed inside grains (OM, Nital etched)

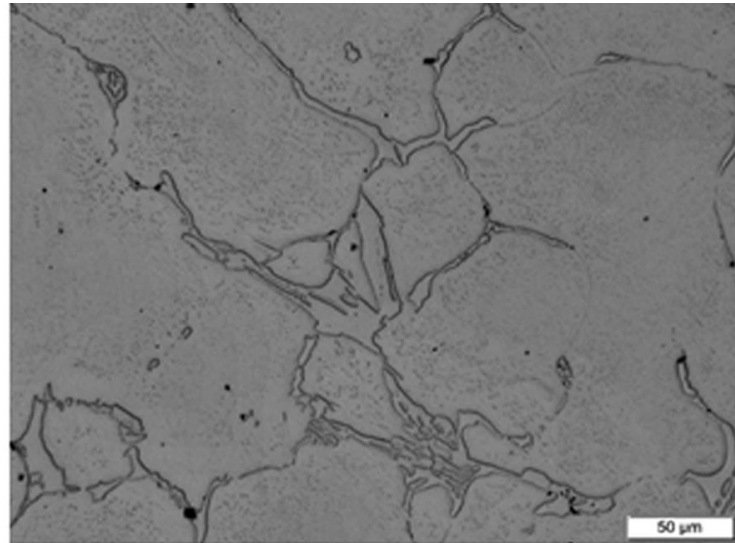

(b) Non-cracked carbides at grain boundaries, intragranular secondary carbides with PFZ around (OM, OPS)

Fig. 10 Microstructures obtained on the stress-free sample (SF300)

Table 5 Grain size and carbide volume fractions obtained on various samples in the longitudinal direction, in different conditions

\begin{tabular}{|c|c|c|}
\hline Sample designation & Grain size $(G)$ according to ASTM E 112 & Carbide volume fractions (\%) $M_{7} C_{3}+M_{2} C$ \\
\hline CT700 & $7.3 \pm 0.1$ & $18.6 \pm 0.4$ \\
\hline СТ300-A & $7.5 \pm 0.1$ & $17.4 \pm 1.5$ \\
\hline СТ300-В & $6.6 \pm 0.5$ & $19.3 \pm 0.7$ \\
\hline
\end{tabular}

For the CT300-B samples which have a similar but more expanded Stage III than that of the CT700 samples, both the low heating rate up to the austenitizing temperature and the relatively longer holding time at this temperature promote $\theta$-cementite dissolution into the fully $\gamma_{1}$ austenitic matrix. The composition of the parent $\gamma_{0}$ austenite phase is assumed to be modified at the same time, as all the elements previously contained in $\theta$ may enter into the composition of $\gamma_{1}$. Newly dissolved elements such as transition elements ( $\mathrm{Cr}$, Mo, and $\mathrm{V})$, or interstitial elements such as $\mathrm{C}$, respectively, act as substitution or insertion elements inside the FCC austenite lattice, which later promote the solution strengthening effect.

In a "sub-saturated" $\gamma_{0}$-austenite containing undissolved tertiary carbides $(\theta)$ such as that of the CT300-A samples, the work hardening behavior should be more influenced by the Orowan mechanism that involves dislocation-precipitate inter- 


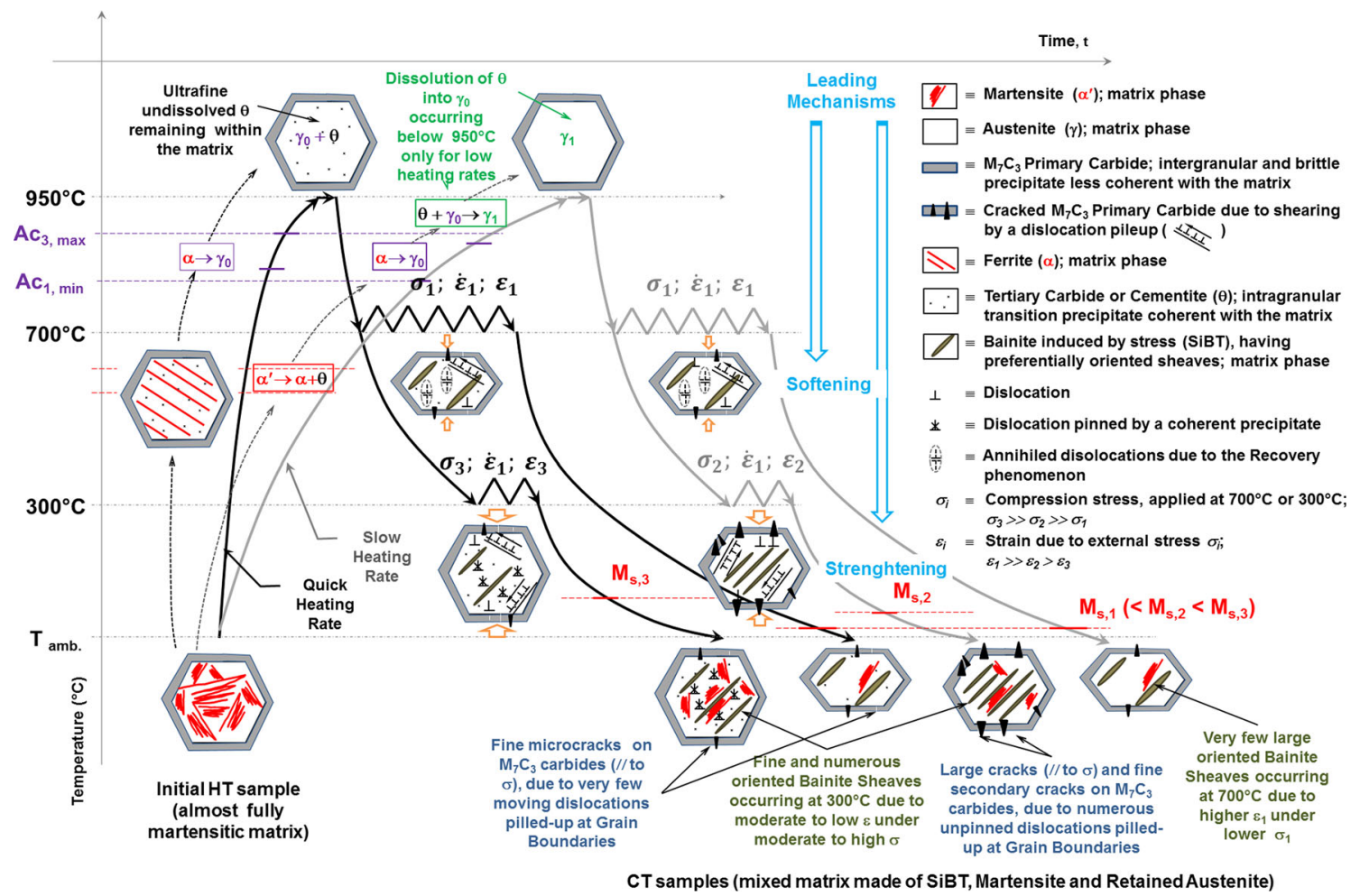

Fig. 11 Sketch of the strengthening and softening mechanisms and the internal damage process (crack initiation on grain boundary primary carbides) occurring on the HCCS alloy at different temperatures

actions in combination with either a phase transformation strengthening mechanism or a softening dynamic recovery phenomenon (Ref 21).

Finally, HCCS behavior at 700 and $300{ }^{\circ} \mathrm{C}$ fits the above definitions of Stages III and IV very well, except for the CT300-A samples, which exhibit Stage III well above that of the other samples. This difference can be explained through the microstructure itself (especially fine tertiary carbides, see section 4.3.1), as it is established that the preliminary reheating and cooling sequence prior to the CT can strongly influence the composition of the matrix.

\subsection{Kinetics of Stress-Induced Bainite Transformation (SIBT)}

4.2.1 Effect of Temperature and Stress on the Initiation of the SIBT. It is known that critical points for phase transformations strongly depend on the chemical composition of the parent austenite that may change the critical phase transformation temperatures. A former study (Ref 26) of a similar grade suggests that the bainitic nose in the continuous cooling transformation (CCT) diagram is far enough to prevent bainitic transformation for the applied cooling rate. However, this assumption is inaccurate according to the current microstructure observations (see section 3.3). In addition, the uniaxial applied stress can increase the start of the bainitic reaction while hindering the transformation of non-favorable oriented grains at the same time (Ref 27, 28).

Optical micrographs of samples that have undergone CTs either at $300{ }^{\circ} \mathrm{C}$ (Fig. 7a and 8a) or at $700{ }^{\circ} \mathrm{C}$ (Fig. 9a) show typical bainitic sheaves oriented following preferential direc- tions, contrary to the stress-free samples (Fig. 10a), which exhibit haphazardly distributed sheaves of bainite. At the same time, the microstructure of the samples tested at $700{ }^{\circ} \mathrm{C}$ is different from that of the samples tested at $300{ }^{\circ} \mathrm{C}$. In the former sample, bainitic sheaves are thicker but in relatively low quantity with a more limited number of orientations. These results are in good agreement with Hase et al. (Ref 27) who found that stressassisted transformation results in large blocks of bainite in identical orientation, the sheaves growing under the influence of stress being thicker than those occurring without stress. In addition, the fact that bainitic sheaves look thicker in the CT700 samples than in the CT300 specimens also suggests a "coarsening" phenomenon that occurs on the sheaf-like microstructure due to the higher transformation temperature (Ref 27).

4.2.2 Effect of Temperature and Stress on the Growth of the SIBT (Amount of Retained Austenite). The retained austenite seems to be present in a higher amount in the CT700 samples than in the CT300. The fact that the apparent amount of bainitic sheaves seems to decrease with the increasing temperature of the CTs seems to be consistent with previous works (Ref 29-32), where it is shown that prior strain or prior stress of the parent austenite greatly influences the subsequent phase transformations during the cooling stage, especially the bainitic transformation.

Yang et al. (Ref 29) and Liu et al. (Ref 30) reinforce the fact that the prior deformation of austenite allows its mechanical stabilization in such a way that the subsequent bainitic transformation is significantly delayed, respectively, in isothermal and in continuous cooling conditions.

Jin et al. (Ref 31 ) found that the isothermal decomposition of deformed austenite into bainite is significantly promoted as 
the incubation period is shortened with increasing strain rate. In the same study, it is noted that the start of isothermal bainite formation increases when the parent austenite phase is deformed. Most recently, Gong et al. (Ref 32) have found that the plastic deformation of the austenite phase accelerates the bainite transformation at a low temperature $\left(300{ }^{\circ} \mathrm{C}\right.$, for a medium alloy steel), whereas the effect on the same transformation is reduced at a higher temperature $\left(600{ }^{\circ} \mathrm{C}\right)$. They established that the difference between the two temperatures is ascribed to the dislocation structure introduced in the parent austenite phase, which remains on the active slip planes especially at the lower temperature. These dislocations later assist the bainite transformation under strong variant selection.

Nevertheless, the above findings may not be considered contradictory if additional information is taken into account. Bhadeshia et al. (Ref 27, 28, 33-35) found that the compressive uniaxial stress increases the bainite start temperature, accelerates the transformation rate, and causes microstructural alignment presented by typical sheaves in selected crystallographic variants of bainite preferentially formed on planes of maximum shear stress. In the meantime, the non-favorable directions are hindered by the same external stress because the shape deformation of a bainite plate does not comply with the external stress; therefore, they should remain austenitic.

Retained austenite that is weakly etched by nital reagent seems to be still present in the CT700 samples (Fig. 9a), in an amount which is lower than that of both the CT300-A (Fig. 7a) and CT300-B samples (Fig. 8a). In addition, the typically oriented bainitic sheaves observed in the final microstructure of the CT700 samples are larger than those found in the samples compressed at $300{ }^{\circ} \mathrm{C}$, thus confirming their origin from the stressed material. Note that stress-free deformed austenite grains do not allow variant selections for bainite transformation and yield to haphazardly distributed sheaves of bainite (Ref 36) as observed in the SF300-B sample (Fig. 10a).

4.2.3 Conclusions on SIBT. It seems that the stress applied at both 300 and $700{ }^{\circ} \mathrm{C}$ allows bainitic transformation under variant selection. The retained and deformed austenite at $700{ }^{\circ} \mathrm{C}$ exhibits a mechanical stabilization that avoids further transformation into bainite, explaining why the volume fraction of bainite formed at $700{ }^{\circ} \mathrm{C}$ due to external stress is lower than the amount of bainite formed at $300{ }^{\circ} \mathrm{C}$.

In addition, higher strains are observed on the samples compressed at $300{ }^{\circ} \mathrm{C}$, especially when the specimens were previously submitted to a low reheating rate up to the austenitization temperature. Such large strains lead to a high amount of bainite that is issued both from the conventional phase transformation, which is linked to thermal history, and from the SIBT.

\subsection{Carbide Influence on Hardening and Damage Mechanisms at $300^{\circ} \mathrm{C}$}

4.3.1 Transition or Tertiary Carbides. It is important to specify why tertiary carbides are called either transition carbides or $\theta$-cementite $\left(\mathrm{M}_{3} \mathrm{C}\right)$ in the present work.

First, if isothermal conditions such as those achieved during the tempering heat treatment of high alloyed steels are considered, then we are dealing with a moderate heating rate up to a temperature well below $\mathrm{Ac}_{1}$ with holding times from tens of hours. The long exposure times are needed both to allow an adequate incubation time for the so-called "secondary" carbide precipitation into the tempered martensitic matrix, and to promote further destabilization of retained austenite during the subsequent cooling (Ref 2, 6-8, 37-39). For long aging times, "secondary carbides" may also undergo transformation into species that are more stable depending on both the temperature and the alloying elements. According to DurandCharre (Ref 37), the first carbide to precipitate from the martensitic matrix in the range 500-600 $\mathrm{C}$ during the tempering of alloy steels is $\theta$-cementite $\left(\mathrm{M}_{3} \mathrm{C}\right)$, prior to a partial dissolution that allows carbon released and further combination with other elements whose carbides are more stable. The same result was obtained by Shtansky et al. (Ref 38), whose study focuses on the decomposition of fresh martensite just below $\mathrm{Ac}_{1}$ on an $\mathrm{Fe}-17 \mathrm{Cr}-0.5 \mathrm{C}$ alloy. In almost all the previous studies, the initial precipitates are often strongly coherent with the matrix, with well-established orientation relationships and with their nuclei being only a few nanometers in size. The coherency with the matrix may be gradually lost with prolonged high temperature exposure due to a possible coarsening phenomenon, especially for carbides with complex crystal structures and low heat for formation $\left(\mathrm{M}_{7} \mathrm{C}_{3}, \mathrm{M}_{6} \mathrm{C}\right.$, and $\left.\mathrm{M}_{23} \mathrm{C}_{6}\right)$. Therefore, $\theta$-cementite $\left(\mathrm{M}_{3} \mathrm{C}\right)$ precipitating during tempering under isothermal conditions can be considered as nuclei for more stable carbides which appear later within the martensite matrix, at the expense of the primary $\theta$-cementite.

As a second step, if continuous heating conditions up to the completion of the austenite transformation are considered, then phase transformations within the matrix of the HCCS alloy will range between 570 and $860{ }^{\circ} \mathrm{C}$ (see the dilatometric curve in Fig. 4). Just below $\mathrm{Ac}_{1}$ and prior to austenite transformation, the fresh martensitic matrix will decompose into ferrite and $\theta$ cementite $\left(\mathrm{M}_{3} \mathrm{C}\right)(\operatorname{Ref} 37,38)$. Between the points $\mathrm{Ac}_{1}$ and $\mathrm{Ac}_{3}$, the ferrite matrix will be transformed into austenite under an allotropic transformation, while $\theta$-cementite will remain mostly undissolved or untransformed, due to the continuous heating conditions (Ref 25, 38, 39).

As the continuous heating conditions of the HCCS alloy are far away from the equilibrium, the complete transformation of metastable cementite into more stable $\mathrm{Cr}$-rich carbides may occur neither below $\mathrm{Ac}_{1}$ nor later during the austenite transformation. Therefore, it has been assumed that $\theta$-cementite remains present and untransformed within the matrix either after its nucleation in the fresh martensite, or later when precipitating from the decomposed martensite, below $\mathrm{Ac}_{1}$.

At the end of austenite transformation, the HCCS alloy is assumed to be composed of a fully austenite matrix containing ultrafine carbides mainly made of undissolved $\theta$-cementite $\left(\mathrm{M}_{3} \mathrm{C}\right)$, and possible "stable" carbides coming from the decomposition of partially dissolved $\theta$-cementite. Above $\mathrm{Ac}_{3}$, $\theta$-cementite $\left(\mathrm{M}_{3} \mathrm{C}\right)$ and other species will undergo dissolution within austenite in a temperature range whose width varies depending both on the chemical composition of the carbides, and on the heating rate. In fact, $\mathrm{Cr}$ is known to enhance cementite stability at high temperature, because retained carbide dissolution in austenite is not controlled by high diffusion rates of interstitial carbon, but by low diffusion rates of substitutional elements at the interfaces (Ref 25, 37-39). In addition, high heating rates may promote the so-called cementite remnants, which consist of undissolved particles within the austenite matrix up to $1000{ }^{\circ} \mathrm{C}(\operatorname{Ref} 40)$.

From the above discussion, tertiary $\theta$-cementite is referred to as transition carbide because it can be transformed into more stable species depending on the reheating route. In addition, $\theta$-cementite $\left(\mathrm{M}_{3} \mathrm{C}\right)$ that appears from fresh martensite decom- 
position prior to austenite transformation is clearly different from the one which precipitated earlier within the tempered martensitic matrix, at a lower temperature. The cementite that precipitated later can remain undissolved within the austenite matrix above point $\mathrm{Ac}_{3}$, due to both the high heating rates and the enhanced stability by substitutional elements partitioned into cementite.

As a consequence, transition carbides remained ultrafine and coherent with the $\gamma_{0}$-austenite matrix under a high heating rate up to $950{ }^{\circ} \mathrm{C}$ (A samples). Conversely, at least the coarsening of these tertiary carbides with a loss of their coherency with the austenite matrix is achieved under low heating rate conditions (B samples). Otherwise, partial to complete dissolution of these carbides might occur to yield supersaturated $\gamma_{1}$-austenite. Such an assumption of the increase of the dissolution temperature of the transition carbides with the heating rate was well established in a previous dilatometric study (Ref 41).

In conclusion, the reason for the higher strengthening effect observed at $300{ }^{\circ} \mathrm{C}$ for the CT300-A samples when compared to the CT300-B samples may be related to the presence of undissolved ultrafine and coherent transition carbides in the former samples that should heavily impede dislocation glide under the Orowan mechanism (Ref 21, 24). These undissolved carbides are assumed to be mainly composed of $\theta$-cementite $\left(\mathrm{M}_{3} \mathrm{C}\right)$ that precipitated first. They are also assumed to be stable due to both the presence of $\mathrm{Cr}$ and to the continuous heating conditions that delay transformations into other stable carbides. Similar transition carbides might have been more or less dissolved in the CT300-B samples due to their low reheating rate. Finally, the difference in total elongation between the CT300-A and CT300-B samples is linked to the fact that the grains of the former, which are full of undissolved tertiary carbides, are less deformable than those of the latter.

4.3.2 Secondary Carbides. Secondary carbides present in the HCCS alloy consist of $\mathrm{M}_{23} \mathrm{C}_{6}$ carbides that are widespread inside grains while leaving the PFZs away and close to the grain boundaries (Fig. 3, 7c, 8c, 9b, and 10b). These carbides are enriched in $\mathrm{Cr}$ but their Mo content increases close to the grain boundaries. The secondary carbides are assumed to enhance the overall hardness of the matrix (Ref 2). In addition, secondary carbides are also assumed to be present in a similar amount in all the compressed samples as they remain undissolved after the reheating stage up to $950{ }^{\circ} \mathrm{C}$ prior to compression, regardless of the reheating rate previously used. But contrary to tertiary carbides, the secondary carbides may have little influence on the strengthening effect due to the very few coherency relationships with the newly formed austenite.

4.3.3 Primary Carbides. Primary carbides are made of Cr-rich $\mathrm{M}_{7} \mathrm{C}_{3}$ carbides and Mo-rich $\mathrm{M}_{2} \mathrm{C}$ carbides, which are located at grain boundaries. But only the $\mathrm{M}_{7} \mathrm{C}_{3}$ carbides, which represent the majority of the grain boundary carbides, contain more or less cracks that are related to the total elongation achieved under the external compression stress applied (Fig. 7b, 8b, 9b). In addition, the maximum elongation under compression at $300{ }^{\circ} \mathrm{C}$ seems to be related to the progress of the internal damage, as the CT300-A samples exhibit a total elongation lower than that achieved on the CT300-B samples.

Focusing on the crack path, it is made of primary carbides containing cracks parallel to the external compression stress, which correspond to the beginning of the internal damage process (CT300-A samples, Fig. 7b). With increasing strain, the crack path changes to a more complex oriented one
(CT300-B samples, Fig. 8b). Therefore, it could be assumed that the primary cracks parallel to the external stress correspond to the initiation of the internal failure mechanism, which is in good agreement with Dünckelmeyer et al. (Ref 42). They found that, for similar carbides, primary cracking is always parallel to the loading direction. The crack occurs when the normal stress of the carbide induced by the plastic deformation of the surrounding matrix is exceeded. This can be achieved either from dislocation pileups on the grain boundary carbides (Ref 43, 44), or due to micro-stresses resulting from differences between the thermal and the elastic properties of the matrix on the one hand, and of the eutectic carbides on the other (Ref 45).

In addition, Margolin et al. (Ref 46) in an earlier study that focuses on brittle fracture mechanisms set criteria for crack nucleation in the form of micro-discontinuities within the material under external stress. In most cases, the crack preferentially nucleates on a grain boundary carbide because the strength of such a phase is lower than the strength of the carbide/matrix interface. The micro-crack occurs in a carbide when the local stress at the head of the dislocation pileup exceeds the strength of the carbide, while remaining lower than the more resistant carbide/matrix bound at the same time. The same authors also found that the crack nuclei change from carbide micro-cracking to delamination at the carbide/matrix interface, only if higher stresses are reached for the same loading. Then a pore is formed at the carbide/matrix bound due to the existence of anti-parallel dislocation pileups within the interface, due to the higher local stresses. Moreover, Kroon and Faleskog (Ref 44) in a more recent work on ferritic steels established that the cleavage fracture is often initiated on brittle carbide as a result of a fiber loading mechanism in which the stress levels in the carbides are raised while the surrounding ferrite undergoes plastic deformation.

The other cracks especially observed on the CT300-B samples, which are oriented in directions different from that of the external stress, are probably ascribed to the progress of the internal damage process with the micro-plastic strain evolution, which allows the occurrence of other critical shear directions within the carbides.

In conclusion, the primary grain boundary $\mathrm{M}_{7} \mathrm{C}_{3}$ carbides serve as preferential crack initiation sites under external compression stress. The cracking of the carbides occurs due to their brittleness as they do not allow plastic deformation contrary to the surrounding matrix.

4.3.4 Conclusions on the Carbide Influence Strengthening Behavior of HCCS Alloy. Undissolved tertiary carbides significantly strengthen the HCCS alloy under compression stress at $300{ }^{\circ} \mathrm{C}$, in such a way that the cracking that was initiated on grain boundary primary carbides is delayed. The secondary carbides probably increase the matrix hardness but have little influence on the strengthening mechanism itself, regardless of the test temperature. Primary carbides promote crack initiation under external stresses.

\subsection{Enhancement of the Softening and the Damage Phenomena Occurring Under Compression at $700^{\circ} \mathrm{C}$}

For the CT700-A samples subjected to a high heating rate, the assumption of a distinct prior austenite composition can be made together with the occurrence of a higher content of tertiary carbides when compared to CT700-B. At the end of the reheating stage, CT700-A may exhibit a microstructure similar to that of the CT300-A samples subjected to the same thermal 
cycle. However, this difference within the prior austenite composition seems to have little influence on the strengthening behavior of the CT700-A samples as their flow curve is similar to that obtained on the CT700-B samples. In fact, all the samples tested at $700{ }^{\circ} \mathrm{C}$ exhibit a similar flow curve regardless of the heating rate used to reach the austenitization at $950{ }^{\circ} \mathrm{C}$. Therefore, no strengthening effect can be expected from the presence (CT700-A samples) or the lack (CT700-B samples) of undissolved tertiary carbides within the matrix. Consequently, the leading mechanism occurring in the $700{ }^{\circ} \mathrm{C}$ samples during the CTs may correspond to the "softening dynamic recovery" phenomenon, which involves a reduction of dislocation density by mutual annihilation (Ref 47-49). In fact, only a small amount of dislocations may reach the grain boundaries where "brittle" primary carbides are located, prior to their cracking when their strength is exceed by the local stress. Therefore, the carbide micro-cracking observed at $700{ }^{\circ} \mathrm{C}$ may be similar to the mechanism which occurs at $300{ }^{\circ} \mathrm{C}$, with narrow cracks for the higher compression temperature and large and branching cracks for the lower compression temperature.

In conclusion, although high plastic deformation occurs within the grains associated with significant total elongation, only a limited shearing phenomenon occurs on grain boundaries, leading to short cracks within primary carbides. The final result is a smaller fracture strain at 700 than at $300{ }^{\circ} \mathrm{C}$.

\subsection{Link Between the Hardness and the Microstructure of the Studied Samples}

It can be seen that both primary and secondary carbides are present in all the sample batches. Although these carbides are known to enhance hardness, no mention will be made of their possible influence in what follows as it is assumed that they act in the same manner for all the samples.

4.5.1 AC and HT Samples. The minimum and the maximum of the bulk hardness are, respectively, obtained in the AC conditions (AC samples) and in the HT conditions (HT samples). All the other samples exhibit bulk hardness between the previous outer limits (Table 4).

The low hardness achieved in the AC samples is due to the presence of troostite within the matrix, such a phase being softer than bainite and martensite. Conversely, the HT samples that exhibit the maximum bulk hardness contain a matrix almost entirely composed of martensite, the rest being made of retained austenite. In addition, the martensite present in the HT samples is probably supersaturated as all the tertiary carbides have been dissolved during the reheating stage up to $1025^{\circ} \mathrm{C}$, prior to air quenching.

4.5.2 Samples Reheated and Isothermally Compressed During the Cooling Stage. As regards the specimens reheated up to $950{ }^{\circ} \mathrm{C}$ before being or not being submitted to an isothermal compression stress during the cooling stage, the CT300-B samples exhibit the highest values for both the bulk hardness and the hardness inside the grains.

For the compressed samples, the above results can be explained as follows. Due to the low reheating rate up to austenitization, tertiary carbides $(\theta$-cementite) are almost dissolved leading to a supersaturated $\gamma_{1}$ matrix that has an austenitic composition with enhanced carbon and alloying element contents (CT300-B and CT700-B samples). Conversely, $\theta$ will remain undissolved in the matrix of the samples that have been submitted to a high reheating rate (CT300-A and
CT700-A samples) yielding a lower carbon-saturated $\gamma_{0}$ matrix. During the subsequent cooling, the application of compression stress may promote the bainitic transformation under the development of preferential oriented sheaves within certain grains, either at 700 or at $300{ }^{\circ} \mathrm{C}$. The end of the cooling stage down to room temperature is later achieved following the withdrawal of the compression stress. During the final cooling stage of the pre-stressed samples, the austenitic grains that were not transformed into bainite under stress may undergo a martensitic transformation. But either the rate of the martensitic transformation or the hardness of the newly formed martensite will depend on the chemical composition of the parent austenite phase.

For samples compressed at $300{ }^{\circ} \mathrm{C}$, the supersaturated $\gamma_{1}$-austenite present in the CT300-B samples will lead to a martensite with hardness higher than that of the lower carbonsaturated $\gamma_{0}$-austenite found in the CT300-A samples. In addition, the amount of SIBT previously formed at $300{ }^{\circ} \mathrm{C}$ will be higher in the CT300-B than in the CT300-A due to the higher strain achieved in the former specimen. In fact, the lack of tertiary carbides within the austenitic matrix of the CT300-B samples will allow more plastic deformation under stress compared to the CT300-A samples, which still contain undissolved $\theta$ that strengthens the material. In all, more bainite is formed in the CT300-B than in the CT300-A samples and also more martensite exists in the former specimens, thus justifying why both the bulk hardness and the hardness inside the grains, with or without bainite, are higher in the CT300-B than in the CT300-A samples.

For the samples compressed at $700{ }^{\circ} \mathrm{C}$, a similar microstructure is obtained in the CT700-A and CT700-B samples, leading to similar hardness values both in the bulk and inside the grains. Very few oriented bainitic sheaves are isothermally formed under stress at $700{ }^{\circ} \mathrm{C}$ compared to $300{ }^{\circ} \mathrm{C}$. After the withdrawal of the compression stress, a certain amount of martensite is formed from the parent deformed austenite, this amount being higher in grains free of bainite than in grains that already contain bainite. Nevertheless, the content of the untransformed austenite seems to be higher in the CT700 samples than in the CT300 samples, probably due to the relative stability of the former that arises from the higher plastic deformation which occurs at $700{ }^{\circ} \mathrm{C}$ compared to $300{ }^{\circ} \mathrm{C}$. Finally, the hardness values achieved in the CT700 samples, which are between those obtained in the CT300-B and the CT300-A samples, are consistent with the microstructure present in the former samples.

4.5.3 Sample Reheated and Cooled Down Without Stress. For the SF300-B sample, the hardness values in the bulk and inside the grains are lower than those obtained in the CT300-B and CT700-B samples that have been subjected to the same reheating rate. This is because more bainite is formed within the SF300-B sample, this bainite exhibiting sheaves that are haphazardly oriented. Therefore, the bainite present in the SF300-B sample is formed without stress and under continuous cooling conditions, contrary to the SIBT observed in the compressed samples that have been formed isothermally.

In the SF300-B sample, the large amount of bainite that is formed consumes an equivalent proportion of the prior austenite phase, which in turn is no more involved in the subsequent martensitic transformation. Thus, the intrinsic hardening potential of the material, which is the maximum with martensite, is reduced when most of the parent austenite has been previously transformed into bainite. 
4.5.4 Conclusions on the Hardness-Microstructure Relationship. Both the amount and the chemical composition of the phases present within the microstructures achieved at room temperature can justify the hardness values obtained following the various thermo-mechanical routes taken for the studied samples.

Higher amounts of martensite within the microstructure lead to higher hardness values both in the bulk and inside the grains. In addition, enhanced carbon content within the martensite, which comes from the supersaturation of the parent austenite phase, will increase the martensite hardness. Conversely, troostite, when present within the microstructure, yields a sharp drop in the hardness. This is due to the fact that troostite is a soft phase, when compared to retained austenite, bainite, or martensite.

\subsection{Rough Damage Model for Internal Crack Initiation}

Figure 11 shows a sketch of the internal damage mechanism occurring in samples submitted to CTs at 300 and $700{ }^{\circ} \mathrm{C}$. This rough damage model can be described first depending on the temperature, and second depending on the type of austenitic matrix.

When the compression stress is applied at $300{ }^{\circ} \mathrm{C}$ on an austenitic matrix containing undissolved tertiary carbides, high work hardening rates can be expected, as these ultrafine and coherent carbides may pin the dislocations while at the same time impeding their glide toward the grain boundaries. Undissolved tertiary carbides strengthen the matrix in such a way that increased compression stresses are necessary to yield sufficient micro-plastic deformation and new dislocation generation within the grains. In addition, the SIBT which occurs will also account for the strengthening phenomenon. When dislocations are not pinned by intragranular carbides, then the dislocation glide may be possible in the direction of the grain boundaries where primary carbides are located. The presence of PFZs close to the grain boundaries may also promote dislocation gliding within these regions. Subsequent pileup of the dislocations on the primary carbides leads to a shearing process which in turn yields sharp micro-cracks as these species are known to be very brittle. The crack initiation within the grain boundary carbides will then follow the direction of the externally applied stress.

When the compression stress is applied at $300{ }^{\circ} \mathrm{C}$ on a supersaturated austenitic matrix where tertiary carbides have been dissolved, the matrix is softer and it can undergo significant plastic strain under limited externally applied stress. The increase in the compression stress leads to an increase in the dislocation density within the grains. Due to the weak presence of fine precipitates having high coherency with the matrix, such as undissolved tertiary carbides, most of the newly generated dislocations are free to move toward grain boundaries where they will pileup on primary carbides. The crack initiation process will then occur in the same manner as for the HCCS material containing undissolved tertiary carbides, with sharp micro-cracks parallel to the externally applied stress. Similarly, SIBT may also occur under stress. Nevertheless, the applied stress necessary to initiate cracks within the grain boundary carbides will be many times lower than that of the same material, which contains undissolved tertiary carbides. Moreover, the crack path inside the softer material will quickly change to a more complex and branched one. Such a complex crack path will contain, in addition to the large cracks parallel to the direction of the external stress, other micro-cracks which are not parallel to the external stress.

For CTs performed at $700{ }^{\circ} \mathrm{C}$, the leading phenomenon is softening dynamic recovery, which is little influenced by intragranular carbides, these precipitates being made either of the ultrafine tertiary coherent carbides or of the coarse secondary carbides. Very little oriented bainitic sheaves are formed at $700{ }^{\circ} \mathrm{C}$, thus confirming the reduced strengthening phenomenon observed at this temperature. In addition, significant plastic deformation occurs under stress at $700{ }^{\circ} \mathrm{C}$, compared to the samples compressed at $300{ }^{\circ} \mathrm{C}$.

The quoted damage model (Fig. 11) mainly corresponds to the internal crack nucleation process on grain boundary primary carbides $\left(\mathrm{M}_{7} \mathrm{C}_{3}\right)$ under the influence of tertiary carbides $(\theta)$ present or not within the austenite $(\gamma)$ grains. Conversely, the secondary intragranular carbides $\left(\mathrm{M}_{23} \mathrm{C}_{6}\right)$ hardly influence both the strengthening and the softening behaviors of HCCS, probably due to their low coherency relationships with the matrix. Therefore, these carbides are not illustrated on the rough damage model.

Note that the start of the martensitic transformation during cooling is affected both by the carbon content of the parent austenite and the level of the applied stress, thus explaining the different levels of the martensite start temperatures $\left(\mathrm{M}_{\mathrm{S} 1}, \mathrm{M}_{\mathrm{S} 2}\right.$, and $\mathrm{M}_{\mathrm{S} 3}$ points) that are drawn in Fig. 11 .

\section{Conclusions}

HCCS alloy after casting and subsequent hardening treatment is made of a mixed martensite and retained austenite matrix with both $\mathrm{Cr}$-rich $\mathrm{M}_{7} \mathrm{C}_{3}$ and Mo-rich $\mathrm{M}_{2} \mathrm{C}$ primary carbides located at the grain boundaries, and widespread Cr-rich $\mathrm{M}_{23} \mathrm{C}_{6}$ secondary carbides inside the grains.

When reheating the HCCS alloy up to austenitization, the tertiary carbides precipitate from the decomposition of the martensite before the beginning of the austenite transformation. These carbides may undergo subsequent dissolution in the newly formed austenite up to $950{ }^{\circ} \mathrm{C}$, especially if low heating rates are used. High heating rates delay the tertiary carbide dissolution within the austenitic matrix.

Tertiary carbides strongly influence the strengthening behavior of the compressed austenite of the HCCS alloy when they remain undissolved. Their influence on the strengthening mechanism is significant at $300{ }^{\circ} \mathrm{C}$ where they pin dislocations, but more limited at $700{ }^{\circ} \mathrm{C}$, due to the softening recovery phenomenon occurring within the material.

Secondary intergranular carbides remain undissolved when the HCCS alloy is reheated up to $950{ }^{\circ} \mathrm{C}$. These carbides increase the hardness of the matrix inside the grains, but scarcely affect the strengthening behavior of the HCCS alloy.

Primary carbides that are located at grain boundaries represent the critical feature in damage mechanism initiation. This is particularly the case for $\mathrm{M}_{7} \mathrm{C}_{3}$ carbides that crack due to the external compression stress.

Compressed austenite, either at 700 or at $300{ }^{\circ} \mathrm{C}$, yields bainite with preferentially oriented sheaves, this transformation accounting also for the strengthening mechanism of the HCCS alloy.

A rough damage model for internal crack initiation is proposed, which takes into account the composition of the parent austenite matrix and the related strengthening and 
softening mechanisms occurring under an externally applied stress.

\section{Acknowledgments}

The authors warmly thank Marichal Ketin for supplying the material and for their technical support. CARE $\mu$ of the ULg is also thanked for providing SEM/EDS facilities. The authors acknowledge Conicyt (National Commission for Scientific and Technological Research) Chile, for financial help. Interuniversity Attraction Poles Program-Belgian State-Belgian Science Policy P7 INTEMATE is thanked for its support. As research Director of FRS-FNRS, AM Habraken thanks this fund, for financial support.

\section{References}

1. A.M. Bayer, B. Becherer, and T. Vasco, High-Speed Tool Steels. ASM Handbook Vol. 16 Machining, ASM International, Materials Park, 1989, p 51-59

2. Z. Zhang, D. Delagnes, and G. Bernhart, Microstructure Evolution of Hot-Work Tool Steels During Tempering and Definition of a Kinetic Law Based on Hardness Measurements, Mater. Sci. Eng. A, 2004, 380(1), p 222-230

3. J. Lecomte-Beckers, M. Sinnaeve, and J. Tchoufang Tchuindjang, New Trends in Hot Strip Mill Roughing Mills: Characterization of High Chromium Steel and Semi-HSS Grades, Assoc. Iron \& Steel Technol., Vol. 2, 2012, p 1-8

4. K.C. Hwang, S. Lee, and H.C. Lee, Effects of Alloying Elements on Microstructure and Fracture Properties of Cast High Speed Steel Rolls Part I: Microstructural Analysis, Mater. Sci. Eng. A, 1998, 254(1), p 282-295

5. M. Boccalini and H. Goldstein, Solidification of High Speed Steels, Inter. Mater. Rev., 2001, 46(2), p 92-115

6. J.W. Park, H.C. Lee, and S. Lee, Composition, Microstructure, Hardness, and Wear Properties of High-Speed Steel Rolls, Met. Mater. Trans. A, 1999, 30(2), p 399-409

7. H. Fu, Y. Qu, J. Xing, X. Zhi, Z. Jiang, M. Li, and Y. Zhang, Investigations on Heat Treatment of a High-Speed Steel Roll, Jrn. Mat. Eng. Perf., 2008, 17(4), p 535-542

8. S.Z. Qamar, Effect of Heat Treatment on Mechanical Properties of H11 Tool Steel, Jrn. Ach. Mater. Manuf. Eng., 2009, 35(2), p 115-120

9. I. Neira Torres, G. Gilles, J. Tchoufang Tchuindjang, J. LecomteBeckers, M. Sinnaeve, and A.M. Habraken, Study of Residual Stresses in Bimetallic Work Rolls, Adv. Mat. Res., 2014, 996, p 580-585

10. H. Li, Z. Jiang, K.A. Tieu, and W. Sun, Analysis of Premature Failure of Work Rolls in a Cold Strip Plant, Wear, 2007, 263(7), p 1442-1446

11. K.H. Ziehenberger and M. Windhager, Recent Developments in HSM Rougher Rolls: Risks and Chances, Iron Steel Technol., 2006, 3(9), p 38-41

12. R. Liang and A.S. Khan, A Critical Review of Experimental Results and Constitutive Models for BCC and FCC Metals Over a Wide Range of Strain Rates and Temperatures, Int. Jrn. Plast., 1999, 15(9), p 963-980

13. G.Z. Voyiadjis and F.H. Abed, Effect of Dislocation Density Evolution on the Thermomechanical Response of Metals with Different Crystal Structures at Low and High Strain Rates and Temperatures, Arch. Mech., 2005, 57(4), p 299-343

14. J. Liu, H. Chang, R. Wu, T.Y. Hsu, and X. Ruan, Investigation on Hot Deformation Behavior of AISI, T1 High-speed Steel, Mater. Char, 2000, 45(3), p 175-186

15. C.A.C. Imbert and H.J. McQueen, Dynamic Recrystallization of A2 and M2 Tool Steels, Mater. Sci. Eng. A, 2001, 313(1), p 104-116

16. I. Tamura, M. Ibaraki, and H. Nozaki, Some Experiments on Ausforming of Tool Steels, Trans. JIM., 1996, 7(4), p 248-252

17. D. Jandova, L.W. Meyer, B. Masek, Z. Novy, D. Kesner, and P. Motycka, The Influence of Thermo-mechanical Processing on the Microstructure of Steel 20MoCrS4, Mater. Sci. Eng. A, 2003, 349(1), p 36-47

18. T. Shigeta, A. Takada, H. Terasaki, and Y.-I. Komizo, The Effects of Ausforming on Variant Selection of Martensite in Cr-Mo Steel, Qart. Jrn. Jpn. Weld. Soc., 2013, 31(4), p 178s-182s
19. P.C.J. Gallagher, The Influence of Alloying, Temperature, and Related Effects on the Stacking Fault Energy, Met. Trans., 1970, 1(9), p 2429 2461

20. S.R. Kalidindi, Modeling The Strain Hardening Response of Low SFE FCC Alloys, Int. Jrn. Plast., 1998, 14(12), p 1265-1277

21. U.F. Kocks and H. Mecking, Physics and Phenomenology of Strain Hardening: The FCC Case, Prog. Mater. Sci., 2003, 48(3), p 171-273

22. K. Maruyama, K. Sawada, J. Koike, H. Sato, and K. Yagi, Examination of Deformation Mechanism Maps in 2.25Cr-1Mo Steel by Creep Tests at Strain Rates of $10^{-11}$ to $10^{-6} \mathrm{~s}^{-1}$, Mater. Sci. Eng. A, 1997, 224(1), p 166-172

23. P.J. Ferreira, J.B. VanderSande, M. AmaralFortes, and A. Kyrolainen, Microstructure Development During High-Velocity Deformation, Met. Mater. Trans. A, 2004, 35(10), p 3091-3101

24. J. Tchoufang Tchuindjang, M. Sinnaeve, and J. Lecomte-Beckers, Influence of High Temperature Heat Treatment on in situ Transformation of Mo-rich Eutectic Carbides in HSS and Semi-HSS Grades, Abrasion 2011, Conference Proceedings, Liege, J. Lecomte-Beckers, J. Tchoufang Tchuindjang, Ed., 2011, p 61-75, ISBN 978-2-8052-0124-0

25. J.-Y. Chae, J.-H. Jang, G. Zhang, K.-H. Kim, J.S. Lee, H.K.D.H. Bhadeshia, and D.-W. Suh, Dilatometric Analysis of Cementite Dissolution in Hypereutectoid Steels Containing Cr, Scripta Mater, 2011, 65(3), p 245-248

26. I. Neira Torres, G. Gilles, J. Tchoufang Tchuindjang, J. LecomteBeckers, M. Sinnaeve, and A.M. Habraken, Prediction of Residual Stresses by FE Simulations on Bimetallic Work Rolls During Cooling, Comp. Meth. Mater. Sci., 2013, 13(2), p 84-91

27. K. Hase, C. Garcia-Mateo, and H.K.D.H. Bhadeshia, Bainite Formation Influenced by Large Stress, Mater. Sci. Technol., 2004, 20(12), p 1499-1505

28. H.K.D.H. Bhadeshia, Bainite in Steels: Transformations, Microstructures and Properties, 2nd ed., IOM Communication Ltd, London, 2001

29. J.R. Yang, C.Y. Huang, W.H. Hsieh, and C.S. Chiou, Mechanical Stabilization of Austenite Against Bainitic Reaction in Fe-Mn-Si-C Bainitic Steel, Mater. Trans. JIM, 1996, 37(4), p 579-584

30. D.S. Liu, G.D. Wang, X.H. Liu, and G.Z. Cui, Mechanical Stabilization of Deformed Austenite During Continuous Cooling Transformation in a C-Mn-Cr-Ni-Mo Plastic Die Steel, Acta Met. Sin., 2009, 11(2), p 93-99

31. X.J. Jin, N. Min, K.Y. Zheng, and T.Y. Hsu, The Effect of Austenite Deformation on Bainite Formation in an Alloyed Eutectoid Steel, Mater. Sci. Eng. A, 2006, 438, p 170-172

32. W. Gong, Y. Tomota, Y. Adachi, A.M. Paradowska, J.F. Kelleher, and S.Y. Zhang, Effects of Ausforming Temperature on Bainite Transformation, Microstructure and Variant Selection in Nanobainite Steel, Acta Mater., 2013, 61(11), p 4142-4154

33. H.K.D.H. Bhadeshia, S.A. David, J.M. Vitek, and R.W. Reed, Stress Induced Transformation to Bainite in Fe-Cr-Mo-C Pressure Vessel Steel, Mater. Sci. Technol., 1991, 7(8), p 686-698

34. H.K.D.H. Bhadeshia, Effect of Stress \& Strain on Formation of Bainite Steels, Hot Workability of Steels and Light Alloys-Composites, (Montreal, Canada), H.J. McQueen, E.V. Konpleva, N.D. Ryan, Ed., Can. Int. Min., 1996, p 543-556

35. S. Kundu, K. Hase, and H.K.D.H. Bhadeshia, Crystallographic Texture of Stress-affected Bainite, Proc. R. Soc. A, 2007, 463(2085), p 23092328

36. A.A. Shirzadi, H. Abreu, L. Pocock, D. Klobcar, P.J. Withers, and H.K.D.H. Bhadeshia, Bainite Orientation in Plastically Deformed Austenite, Int. Jrn. Mater. Res., 2009, 100(1), p 40-45

37. M. Durand-Charre, Microstructure of Steels and Cast Irons, Chap. 11, Springer, New York, 2004, p 219-222, ISBN 3-540-20963-8

38. D.V. Shtansky, K. Nakai, and Y. Ohmori, Decomposition of Martensite by Discontinuous-like Precipitation Reaction in an $\mathrm{Fe}-17 \mathrm{Cr}-0.5 \mathrm{C}$ Alloy, Acta Mater, 2000, 48(4), p 969-983

39. G. Miyamoto, H. Usuki, Z.-D. Li, and T. Furuhara, Effects of Mn, Si and $\mathrm{Cr}$ Addition on Reverse Transformation at $1073 \mathrm{~K}$ from Spheroidized Cementite Structure in Fe-0.6 Mass\% C Alloy, Acta Mater., 2010, 58(13), p 4492-4502

40. K.D. Clarke, C.J. Van Tyne, C.J. Vigil, and R.E. Hackenberg, Induction Hardening 5150 Steel: Effects of Initial Microstructure and Heating Rate, Jrn. Mater. Eng. Perf., 2011, 20(2), p 161-168

41. S.-J. Lee and K.D. Clarke, A Conversional Model for Austenite Formation in Hypereutectoid Steels, Met. Mater. Trans. A, 2010, 41(12), p 3027-3031 
42. M. Dünckelmeyer, C. Krempaszky, E. Werner, G. Hein, and K. Schörkhuber, On the Causes of Banding Failure, Proc. of METEC InSteelCon 2011, STEELSIM, 2011, p 1-9

43. P.W. Shelton and A.S. Wronski, Cracking in M2 High Speed Steel, Mater. Sci. Technol., 1983, 17(11), p 533-540

44. M. Kroon and J. Faleskog, Micromechanics of Cleavage Fracture Initiation in Ferritic Steels by Carbide Cracking, Jrn. Mech. Phys. Sol., 2005, 53(1), p 171-196

45. C.R.S. da Silva and M. Boccalini, Thermal Cracking of Multicomponent White Cast Iron, Mater. Sci. Technol., 2005, 21(5), p 565-573
46. B.Z. Margolin, V.A. Shvetsova, and A. Ya, Varovin, Preliminary Compression of a Material as a Factor in Changing the Brittle Fracture Mechanism for BCC Metals, Str. Mater., 1996, 28(4), p 251-261

47. V. Vodopivec, Dynamic Recovery of Austenite in Low Carbon Steels and its Relationship to the Precipitation of AlN, Jrn. Mater. Sci., 1975, 10(6), p 1082-1084

48. E. Nes, Recovery Revisited, Acta Mater., 1995, 43(6), p 2189-2207

49. L. Kubin, T. Hoc, and B. Devincre, Dynamic Recovery and its Orientation Dependence in Face-centered Cubic Crystals, Acta Mater., 2009, 57(8), p 2567-2575 